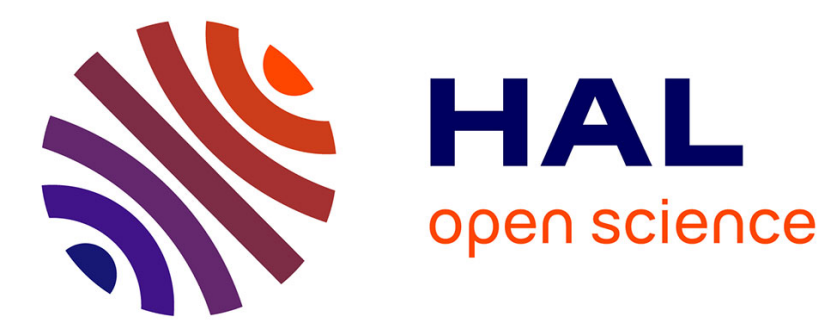

\title{
Vibrations of inclined cables under skew wind
}

Nicola Impollonia, Giuseppe Ricciardi, Fernando Saitta

\section{To cite this version:}

Nicola Impollonia, Giuseppe Ricciardi, Fernando Saitta. Vibrations of inclined cables under skew wind. International Journal of Non-Linear Mechanics, 2011, 10.1016/j.ijnonlinmec.2011.03.006 . hal00758602

\section{HAL Id: hal-00758602 \\ https://hal.science/hal-00758602}

Submitted on 29 Nov 2012

HAL is a multi-disciplinary open access archive for the deposit and dissemination of scientific research documents, whether they are published or not. The documents may come from teaching and research institutions in France or abroad, or from public or private research centers.
L'archive ouverte pluridisciplinaire HAL, est destinée au dépôt et à la diffusion de documents scientifiques de niveau recherche, publiés ou non, émanant des établissements d'enseignement et de recherche français ou étrangers, des laboratoires publics ou privés. 
Vibrations of inclined cables under skew wind

Nicola Impollonia, Giuseppe Ricciardi, Fernando

Saitta

PII: S0020-7462(11)00030-8

DOI: doi:10.1016/j.ijnonlinmec.2011.03.006

Reference: NLM 1822

To appear in: International Journal of Non-

www.elsevier.com/locate/nlm Linear Mechanics

Received date: 5 May 2010

Revised date: 16 February 2011

Accepted date: 18 March 2011

Cite this article as: Nicola Impollonia, Giuseppe Ricciardi and Fernando Saitta, Vibrations of inclined cables under skew wind, International Journal of Non-Linear Mechanics, doi:10.1016/j.ijnonlinmec.2011.03.006

This is a PDF file of an unedited manuscript that has been accepted for publication. As a service to our customers we are providing this early version of the manuscript. The manuscript will undergo copyediting, typesetting, and review of the resulting galley proof before it is published in its final citable form. Please note that during the production process errors may be discovered which could affect the content, and all legal disclaimers that apply to the journal pertain. 


\title{
VIBRATIONS OF INCLINED CABLES UNDER SKEW WIND
}

\author{
Nicola Impollonia ${ }^{1}$, Giuseppe Ricciardi ${ }^{2}$, Fernando Saitta ${ }^{3}$ \\ ${ }^{1}$ Dipartimento DARC, Università di Catania, P.zza Federico di Svevia, 96100 Siracusa, Italy \\ ${ }^{2}$ Dipartimento di Ingegneria Civile, Università di Messina, C.da di Dio, 98166, Villaggio S. Agata, \\ Messina, Italy \\ ${ }^{3}$ ENEA, Centro Ricerche di Bologna, Via Martiri di Monte Sole 4, 40129 Bologna, Italy
}

\begin{abstract}
A non-linear finite element model of inclined cables, i.e. cables with non-leveled supports, in the large displacement and deformation fields is proposed for computing the dynamic response to wind loads which blow in arbitrary direction. The initial equilibrium, assumed as the static configuration under self weight and mean wind component, is defined by a continuous approach, following an iterative procedure which starts from the configuration under self weight only. The proposed formulation, which accounts for longitudinal inertia forces, allows to spot the circumstances when the simplified small-sag approach, adopting longitudinal mode condensation, becomes too crude. Numerical simulations have been performed empoying the Proper Orthogonal Decomposition to lower the computational effort.
\end{abstract}

Keywords: Cable dynamics, Proper Orthogonal Decomposition, W ind forces.

\section{Introduction}

Vibration of cables under wind constitutes an open problem with great implication in practical engineering. Cables are in fact widely used as fundamental structural elements in many applications as bridges, transmission lines, marine risers, cable roof structures. Different sag-to-span ratios are encountered in the various realizations; besides supports can be at the same or at different level. Traditionally, cable dynamics is intended as the time dependent response around the initial static configuration given by the equilibrium under self weight and described by the catenary equation, 
including or not cable extensibility or, for shallow cables, by the parabolic approximation [1][2]. The former needs the solution of a nonlinear equation in order to find cable tension whereas the static deformed shape is written by means of an expression involving hyperbolic functions. Parabolic assumption does not apply to cables with sag-to-span ratio greater than 1:8, and may lead to crude approximation for inclined cables [1].

The time dependent response is usually determined with reference to the initial static equilibrium following the work of Irvine and Caughey [3] in which continuous linear modes of the elastic cable are derived for the in-plane and out-of-plane vibration. While cable elasticity has been shown to be essential in the dynamic of low-sagged cables, the along cable inertia forces are usually neglected by statically condensing the longitudinal equation of motion [4]-[6]. However, the noncondensed approach is more appropriate for describing motion of inclined cables, which exhibit peculiar dynamic behaviour as testified by the veering in frequency curves and the associated hybrid mode shapes [7].

Although a lot of works pay attention to linear and nonlinear cable dynamics, less effort has been devoted to study wind exposed cables. M ost of the works about wind-excited cables are related to stay cables or transmission lines and are focused to instability phenomena, such as rainwind or dry-state galloping induced vibration, vortex shedding, galloping of ice-covered cables [8][11]. Different papers deal with vibration mitigation by means of external devices such as viscous dampers [12][13]. Besides, several experimental works in wind tunnels are devoted to all these problems [14]-[16].

Recently some papers addressed nonlinear cable analysis under turbulent wind. Di Paola et al. [17] use a continuous model for shallow cables assuming a static initial shape based on the parabolic approximation under self weight. The wind is considered to blow perpendicular with respect to the vertical plane containing the cable and M ontecarlo simulation is adopted to evaluate cable stochastic response. The case of a cable network under wind loading is considered in [18]. 
Gattulli et al. [19] attack the problem by a continuous and a FE approach simulating wind time histories through Shinozuka method [20]; a linear elastic cable behaviour was assumed in the large displacement and small deformation field, applying an updated Lagrangian approach. When the continuous approach is pursued, the expansion of the turbulence components as a superposition of structural modes leads to a reduced wind model which may be viewed as a deterministic version of the well known Proper Orthogonal Decomposition (POD), used in order to determine a reduced stochastic wind field [21]-[23]. The initial shape of the cable is defined by considering self weight and mean wind; thus, the cable lays in a rotated plane with respect to the vertical one, and the layout is defined by means of the parabolic or nonlinear catenary equation according to displacement amplitude. However, the wind is supposed to blow horizontally in the orthogonal direction with respect to cable plane and longitudinal inertia is not accounted for.

A recent paper by Carassale and Piccardo [24], proposes a continuous model to evaluate the response of shallow cables to turbulent wind around the initial configuration due to self weight. The model adopts a refined wind forces characterization; drag forces act in the plane of the cross sections of the cable and the cable-wind relative velocity is expanded in series up to the third order, introducing nonlinear wind forces contributions. The authors show that the probability distribution of cable response under wind, calculated by means of $M$ ontecarlo simulation, can be significantly non-Gaussian.

\section{Purpose of the paper}

The formulation proposed herein accounts for longitudinal inertia forces and considers the exact initial equilibrium according to the elastic catenary equation. In this way, the cable model is sufficiently refined to include different scenarios.

The wind is supposed to act horizontally in any given direction, its tangential component is neglected and only the wind component laying in the plane of the cross section is considered as drag force. The initial equilibrium of the cable under self weight and constant wind is reproduced 
by means of an iterative procedure, starting from the configuration due to self weight only. A finite element model is implemented to evaluate cable dynamics under turbulent wind adopting a modal transformation which retains only a chosen number of modes so to lower the computational effort. An expansion of drag forces is adopted following [24] and [25] and the aerodynamic damping matrix is added to structural damping. Wind velocity and cable cross-section are such as to operate in the sub-critical range. The numerical time domain solution is performed in the reduced modal space by simulating coupled modal forces, making use of the POD. So operating the multivariatemulticorrelated process can be transformed into a superposition of multivariate-monocorrelated processes.

The proposed procedure for the nonlinear wind response evaluation of an arbitrarily sagged cable, eventually inclined with supports at different height, can be summarized by the following steps:

- Define mean wind component and direction;

- Determine the initial equilibrium configuration of the cable under mean wind by an iterative procedure;

- Define the finite element model for dynamic analysis under turbulent wind;

- A ssign the turbulent wind Power Spectral Density, and determine the cable modal forces with reference to initial equilibrium configuration;

- Evaluate the nonlinear response by using a reduced modal model.

Such operations will be discussed in the following sections and applied to different example problems regarding low-sagged, sagged and inclined cables. The A ppendix summarizes the order in which the Equations given in sections 3-6 should be applied. 


\section{Wind forces on the cable}

The cable configurations which will be considered are the followings: the static equilibrium under self weight, $C_{I}$; the static equilibrium under self weight and mean wind, $C_{I I}$; the dynamic vibrations produced by wind fluctuations, $C_{I I I}(t)$; as depicted in Figure 1 . Configuration $C_{I I}$ will be evaluated by an iterative procedure as described in Section 4 and plays the role of initial equilibrium configuration around which dynamic vibrations are evaluated. The Lagrangian coordinate $s_{0}$ represents the length of the unstrained cable between the generic point and the cable origin. Denoting with $L_{0}$ the unstrained cable length, it will be $0 \leq s_{0} \leq L_{0}$. Starting from the unstrained configuration, the cable undertakes the different equilibrium configurations changing its length. A segment on the unstrained cable of length $d s_{0}$, will measure $d s_{i}$ in the strained configurations $C_{i}($ $i=I, I I, I I I)$. A ccording to a Lagrangian approach, the position of cable points in an orthogonal reference system is still referred to $s_{0}$. The generic cable point position in the different configurations is located by an orthogonal reference systems through the vectors $\mathbf{x}_{I}\left(s_{0}\right), \mathbf{x}_{I I}\left(s_{0}\right)$ and $\mathbf{x}_{I I I}\left(s_{0}, t\right)$.

The distributed drag force on the cable can be defined through a three dimensional vector function as follows:

$\mathbf{f}_{D}\left(s_{0}, t\right)=\frac{1}{2} \rho c_{D} b\left\|\mathbf{w}\left(s_{0}, t\right)-\dot{\mathbf{z}}\left(s_{0}, t\right)\right\|\left[\mathbf{w}\left(s_{0}, t\right)-\dot{\mathbf{z}}\left(s_{0}, t\right)\right]$

where $\|\cdot\|$ is the norm operator; $\rho$ is air density; $c_{D}$ is the drag coefficient; $b$ is the diameter of the cross section of the cable; $\mathbf{w}\left(s_{0}, t\right)$ is the effective wind velocity vector, that is the projection of the wind velocity vector on the cable cross section at abscissa $s_{0} ; \dot{\mathbf{z}}\left(s_{0}, t\right)$ is the projection of the cable velocity vector $\dot{\mathbf{u}}\left(s_{0}, t\right)$ on the same plane. It will be assumed that the drag coefficient $c_{D}$ does not depend from Reynold's number ( $\mathrm{Re})$, because the flow is considered to be in the sub-critical range ( $\operatorname{Re}<3.510^{5}$ ) so that dry-state galloping or rain-induced instability phenomena are ruled out. 
Making the hypothesis of turbulence in the direction of mean wind only and considering the undisturbed wind velocity vector $\mathbf{v}\left(\mathbf{x}_{I}\left(s_{0}\right), t\right)=\mathbf{v}\left(s_{0}, t\right)=v\left(s_{0}, t\right) \mathbf{k}$, with constant direction defined by the versor $\mathbf{k}$, the effective wind velocity is written, with reference to configuration $C_{I I}$ (see Fig. 2), as follows:

$$
\mathbf{w}\left(s_{0}, t\right)=w\left(s_{0}, t\right) \mathbf{j}\left(s_{0}\right)
$$

where $w\left(s_{0}, t\right)$ and $\mathbf{j}\left(s_{0}\right)=\mathbf{j}\left(\mathbf{x}_{I I}\left(s_{0}\right)\right)$ are, respectively, the modulus and the versor of the effective wind velocity. By introducing the projection matrix:

$$
\Gamma\left(s_{0}\right)=\mathbf{I}-\mathbf{t}\left(s_{0}\right) \mathbf{t}^{T}\left(s_{0}\right)
$$

where $\mathbf{I}$ is the identity matrix of order three and $\mathbf{t}\left(s_{0}\right)=d \mathbf{x}_{I I} / d s_{I I}$ is the tangent versor to the cable with reference to configuration $C_{I I}$ (see Fig. 2), the quantities in Eq. (2) become:

$$
\begin{aligned}
& \mathbf{j}\left(s_{0}\right)=\frac{1}{\gamma\left(s_{0}\right)} \boldsymbol{\Gamma}\left(s_{0}\right) \mathbf{k} \\
& w\left(s_{0}, t\right)=v\left(s_{0}, t\right) \gamma\left(s_{0}\right)
\end{aligned}
$$

In the previous equations, $\gamma\left(s_{0}\right)$ is defined as follows:

$$
\gamma\left(s_{0}\right)=\left\|\boldsymbol{\Gamma}\left(s_{0}\right) \mathbf{k}\right\|
$$

If the wind velocity is split into mean and turbulent components:

$$
v\left(s_{0}, t\right)=\bar{v}\left(s_{0}\right)+\tilde{v}\left(s_{0}, t\right)
$$

Eq. (2) can be rewritten as:

$$
\mathbf{w}\left(s_{0}, t\right)=\overline{\mathbf{w}}\left(s_{0}\right)+\tilde{\mathbf{w}}\left(s_{0}, t\right)
$$

where:

$$
\overline{\mathbf{w}}\left(s_{0}\right)=\bar{w}\left(s_{0}\right) \mathbf{j}\left(s_{0}\right)=\bar{v}\left(s_{0}\right) \gamma\left(s_{0}\right) \mathbf{j}\left(s_{0}\right) \quad \tilde{\mathbf{w}}\left(s_{0}, t\right)=\tilde{w}\left(s_{0}, t\right) \mathbf{j}\left(s_{0}\right)=\tilde{v}\left(s_{0}, t\right) \gamma\left(s_{0}\right) \mathbf{j}\left(s_{0}\right)
$$

According to the quasi-static approach, we assume the hypothesis $\mathbf{w} \gg \dot{\mathbf{z}}$, and expand the drag force in Taylor series with respect to $\dot{\mathbf{z}}$, following [24]-[25]. By retaining terms up to the first order one gets: 
$\mathbf{f}_{D}\left(s_{0}, t\right)=\mathbf{f}_{D(\dot{\mathbf{z}}=0)}+\left[\nabla_{\dot{\mathbf{z}}^{\prime}} \mathbf{f}_{D}^{T}\right]_{(\dot{\mathrm{z}}=\mathbf{0})}^{T} \dot{\mathbf{z}}+\ldots$

where:

$$
\nabla_{\dot{\mathbf{z}}}^{T}=\left[\begin{array}{lll}
\frac{\partial}{\partial \dot{z}_{1}} & \cdots & \frac{\partial}{\partial \dot{z}_{3}}
\end{array}\right]
$$

The first term in the expansion:

$$
\mathbf{f}_{D(\mathbf{z}=0)}=\frac{1}{2} \rho c_{D} b w^{2}\left(s_{0}, t\right) \mathbf{j}\left(s_{0}\right)
$$

by substituting the mean and turbulent parts, can be rew ritten as follows:

$$
\mathbf{f}_{D(\dot{\boldsymbol{z}}=0)}\left(s_{0}, t\right)=\frac{1}{2} \rho c_{D} b\left[\bar{w}^{2}\left(s_{0}\right)+2 \bar{w}\left(s_{0}\right) \tilde{w}\left(s_{0}, t\right)+\tilde{w}^{2}\left(s_{0}, t\right)\right] \mathbf{j}\left(s_{0}\right)
$$

Furthermore, as the along-wind turbulence only is considered and $\bar{w}\left(s_{0}\right)>\tilde{w}\left(s_{0}, t\right) \forall t$, neglecting the quadratic component of turbulence, Eq. (13) becomes:

$$
\mathbf{f}_{D(\dot{z}=0)}\left(s_{0}, t\right)=\overline{\mathbf{f}}_{D(\dot{z}=0)}\left(s_{0}\right)+\tilde{\mathbf{f}}_{D(\dot{z}=0)}\left(s_{0}, t\right)
$$

where:

$$
\begin{aligned}
& \overline{\mathbf{f}}_{D(\dot{z}=0)}\left(s_{0}\right)=\frac{1}{2} \rho c_{D} b \bar{w}^{2}\left(s_{0}\right) \mathbf{j}\left(s_{0}\right)=\frac{1}{2} \rho c_{D} b \bar{v}^{2}\left(s_{0}\right) \gamma^{2}\left(s_{0}\right) \mathbf{j}\left(s_{0}\right) \\
& \tilde{\mathbf{f}}_{D(\dot{z}=0)}\left(s_{0}, t\right)=\rho c_{D} b \bar{w}\left(s_{0}\right) \tilde{w}\left(s_{0}, t\right) \mathbf{j}\left(s_{0}\right)=\rho c_{D} b \bar{v}\left(s_{0}\right) \tilde{v}\left(s_{0}, t\right) \gamma^{2}\left(s_{0}\right) \mathbf{j}\left(s_{0}\right)
\end{aligned}
$$

The second term in Eq.(10) can be written as follows:

$$
\left[\nabla_{\dot{\mathbf{z}}_{D}} \mathbf{f}_{(\dot{\mathrm{z}}=\mathbf{0})}^{T}\right]_{\mathbf{\mathbf { z }}}^{T}=-\frac{1}{2} \rho c_{D} b \bar{w}\left(s_{0}\right)\left[\mathbf{I}+\mathbf{j}\left(s_{0}\right) \mathbf{j}^{T}\left(s_{0}\right)\right] \dot{\mathbf{z}}-\frac{1}{2} \rho c_{D} b \tilde{w}\left(s_{0}, t\right)\left[\mathbf{I}+\mathbf{j}\left(s_{0}\right) \mathbf{j}^{T}\left(s_{0}\right)\right] \dot{\mathbf{z}}
$$

The aerodynamic damping force is due to the first term in Eq.(17), whereas the second term leads to an aeroelastic forcing quantity which is neglected herein. The vector $\dot{\mathbf{z}}\left(s_{0}, t\right)$ is obtained from the cable velocity $\dot{\mathbf{u}}\left(s_{0}, t\right)$ by the relationship:

$$
\dot{\mathbf{z}}\left(s_{0}, t\right)=\boldsymbol{\Gamma}\left(s_{0}\right) \dot{\mathbf{u}}\left(s_{0}, t\right)
$$

Therefore, the aerodynamic damping force can be written as follows: 


$$
\mathbf{f}_{\text {ad }}\left(s_{0}, t\right)=-\frac{1}{2} \rho c_{D} b \bar{v}\left(s_{0}\right) \gamma\left(s_{0}\right)\left[\mathbf{I}+\mathbf{j}\left(s_{0}\right) \mathbf{j}^{T}\left(s_{0}\right)\right] \boldsymbol{\Gamma}\left(s_{0}\right) \dot{\mathbf{u}}\left(s_{0}, t\right)
$$

\section{Equilibrium under self weight and mean wind}

The mean wind force given by Eq. (15) is related to the tangent versor to the cable with reference to configuration $C_{I I}$, according to Eqs. (3), (4) and (6). Such a configuration, i.e. the equilibrium under self weight and mean wind, may be detected by an iterative procedure here conducted for the case of discretized wind forces. Thus, the mean wind force is applied as equally spaced point loads at abscissas $s_{0, i}$, each of which is the resultant on a defined interval $\Delta s_{0}$; the $i$-th point load with $i=1,2, \ldots, n_{p}$ can be written as follows:

$$
\mathbf{P}_{i}=\overline{\mathbf{f}}_{D(\dot{z}=0)}\left(s_{0, i}\right) \Delta s_{0}=\frac{1}{2} \rho c_{D} b \bar{w}^{2}\left(s_{0, i}\right) \Delta s_{0} \mathbf{j}\left(s_{0, i}\right)
$$

The classic catenary approach which finds initial static shape of the cable under self weight [1] is extended to allow point loads, generally oriented in space [2]. The equilibrium equation becomes:

$$
T\left(s_{0}\right) \frac{d \mathbf{x}_{I I}}{d s_{I I}}=\mathbf{R}-\mathbf{p} s_{0}-\sum_{i} \mathbf{P}_{i} U\left(s_{0}-s_{0, i}\right)
$$

where $T\left(s_{0}\right)$ is the cable tension; $\mathbf{R}=\left[R_{x_{1}}, R_{x_{2}}, R_{x_{3}}\right]$ is the vector collecting the three components of the cable tension at the first cable end; $\mathbf{p}=\left[\begin{array}{lll}0 & m_{0} g & 0\end{array}\right]^{T}$ represents the distributed forces acting on the cable; $U\left(s_{0}\right)$ is the unitary step function. By using the chain rule of differentiation, $\left(d \mathbf{x}_{\text {II }} / d s_{0}\right)=\left(d \mathbf{x}_{I I} / d s_{I I}\right)\left(d s_{I I} / d s_{0}\right)$, and according to the Hooke's law, $\left(d \mathbf{x}_{I I} / d s_{0}\right)=T\left(s_{0}\right) / E A+1$, Eq. (21) gives:

$$
\mathbf{x}_{I I}\left(s_{0}\right)=\int_{0}^{s_{0}}\left(\mathbf{R}-\mathbf{p} s-\sum_{i} \mathbf{P}_{i} U\left(s-s_{0, i}\right)\right)\left(\frac{1}{E A_{0}}+\frac{1}{T(s)}\right) d s
$$

The vector $\mathbf{R}$ can be derived solving numerically the nonlinear integral equation $\mathbf{x}_{I I}\left(L_{0}\right)=\mathbf{x}_{L}$, i.e. by imposing the end coordinates of the cable. The first iteration considers distributed forces 
corresponding to self weight only $\left(\mathbf{P}_{i}=\mathbf{0}\right)$ and leads to the vertical configuration $C_{I}$. The mean effective wind velocity is evaluated as:

$$
\overline{\mathbf{w}}\left(s_{0, i}\right)=\bar{v}\left(s_{0, i}\right) \gamma\left(s_{0, i}\right) \mathbf{j}\left(s_{0, i}\right)
$$

being $\bar{v}\left(s_{0, i}\right)$ the undisturbed mean wind related to configuration $C_{I}$. The mean wind point forces are derived by Eq. (20); Eq. (22) leads to a new iteration for which the udated versor $\mathbf{j}\left(s_{0}\right)$ is evaluated. A fter few iterations, the procedure converges to configuration $C_{I I}$, which can be written as function of cable abscissa $s_{I I}$, section area $A_{I I}$ and mass $m_{I I}$ by making use of the mass conservation principle. The abscissa $s_{I I}$ can be derived as follows:

$s_{I I}\left(s_{0}\right)=\int_{0}^{s_{0}}\left(T(s) / E A_{0}+1\right) d s$

where $T(s)=\left\|\mathbf{R}-\mathbf{p} s-\sum_{i} \mathbf{P}_{i} U\left(s-\bar{s}_{0, i}\right)\right\|$.

The undisturbed mean wind is defined according to the logarithmic law [26]:

$$
\bar{v}\left(s_{0, i}\right)=\frac{u_{*}}{\kappa} \log \left(\frac{H-x_{I 2}\left(s_{0, i}\right)}{l_{r}}\right)
$$

in which $H$ is the height above ground level of the origin, $u_{*}$ is the shear velocity, $\kappa$ the von Karman coefficient, $l_{r}$ is the roughness length. Assuming that the wind blows horizontally, intersecting the $x_{1}$ axis with an angle $\varphi$, then $\mathbf{k}=\left[\begin{array}{lll}\cos \varphi & 0 & \sin \varphi\end{array}\right]^{T}$.

\section{FEM approach}

In order to simplify the finite element formulation, the response variable will be referred to the updated lagrangian coordinate $s_{I I}$ which is related to $s_{0}$ through Eq. (24). This choice allows a more straightforward element definition and the use of constant length elements. The equation of motion of the cable can be written in the following vector form [27]: 
$\frac{\partial}{\partial s_{I I}}\left[T \frac{\partial \mathbf{u}}{\partial s_{I I}}+E A\left(\frac{\partial \mathbf{u}^{T}}{\partial s_{I I}} \frac{d \mathbf{x}_{I I}}{d s_{I I}}+\frac{1}{2}\left\|\frac{\partial \mathbf{u}}{\partial s_{I I}}\right\|^{2}\right)\left(\frac{d \mathbf{x}_{I I}}{d s_{I I}}+\frac{\partial \mathbf{u}}{\partial s_{I I}}\right)\right]+\mathbf{f}\left(s_{I I}, t\right)=m_{I I} \ddot{\mathbf{u}}$

where $\mathbf{u}\left(s_{I I}, t\right)$ is a continuous vector function which gives cable displacements with reference to configuration $C_{I I}$ (see Figure 1); $\mathbf{f}\left(s_{I I}, t\right)$ represents the distributed dynamic forces on the cable, sum of turbulent wind, $\tilde{\mathbf{f}}\left(s_{I I}, t\right)$, and aerodynamic damping, $\mathbf{f}_{\text {ad }}\left(s_{I I}, t\right)$ :

$\mathbf{f}\left(s_{I I}, t\right)=\tilde{\mathbf{f}}\left(s_{I I}, t\right)+\mathbf{f}_{\text {ad }}\left(s_{I I}, t\right)$

The approximations $s_{I I} \equiv s_{I I I}, m_{I I} \equiv m_{I I I}, A_{I I} \equiv A_{I I I}$ will be adopted and the subscript II will be omitted for the sake of simplicity. In order to derive a finite element solution, the displacement vector is expanded over the element $e$ as follows:

$\mathbf{u}^{e}(s, t)=\mathbf{N}(s) \mathbf{U}^{e}(t)$

where $\mathbf{N}(s)$ is the shape functions matrix defined as follows:

$\mathbf{N}(s)=\left[\begin{array}{ll}\psi_{1}(s) \mathbf{I} & \psi_{2}(s) \mathbf{I}\end{array}\right]$

with:

$\psi_{1}(s)=1-\left(s-s_{A}\right) / \Delta s_{e} ; \quad \psi_{2}(s)=\left(s-s_{A}\right) / \Delta s_{e}$

The identity matrix I has order 3 and $\Delta s_{e}=s_{B}-s_{A}$ is the length of the element. Pre-multiplying the dynamic equilibrium equation for the shape function matrix and by means of integration by parts over the element, between abscissas $s_{A}$ and $s_{B}$, the weak form is obtained:

$$
\begin{aligned}
-\left\{\mathbf{N}^{T}(s)[\right. & \left.\left.T \frac{\partial \mathbf{u}}{\partial s}+E A\left(\frac{\partial \mathbf{u}^{T}}{\partial s} \frac{d \mathbf{x}}{d s}+\frac{1}{2}\left\|\frac{\partial \mathbf{u}}{\partial s}\right\|^{2}\right)\left(\frac{d \mathbf{x}}{d s}+\frac{\partial \mathbf{u}}{\partial s}\right)\right]\right\}_{s_{A}}^{s_{B}} \\
& +\int_{s_{A}}^{s_{B}} \mathbf{B}^{T}\left[T \frac{\partial \mathbf{u}}{\partial s}+E A\left(\frac{\partial \mathbf{u}^{T}}{\partial s} \frac{d \mathbf{x}}{d s}+\frac{1}{2}\left\|\frac{\partial \mathbf{u}}{\partial s}\right\|^{2}\right)\left(\frac{d \mathbf{x}}{d s}+\frac{\partial \mathbf{u}}{\partial s}\right)\right] d s-\int_{s_{A}}^{s_{B}} \mathbf{N}^{T}(s) \mathbf{f}(s, t) d s+\int_{s_{A}}^{s_{B}} m \mathbf{N}^{T}(s) \ddot{\mathbf{u}} d s=\mathbf{0}
\end{aligned}
$$

where $\mathbf{B}=d \mathbf{N}(s) / d s$ is a constant matrix. By introducing Eq. (28), the non linear finite element equation is obtained: 


$$
\mathbf{M}^{e} \mathbf{U}^{e}+\mathbf{K}^{e} \mathbf{U}^{e}+\mathbf{G}\left(\mathbf{U}^{e}\right)=\mathbf{F}^{e}+\mathbf{Q}^{e}
$$

The element mass matrix is given by:

$$
\mathbf{M}^{e}=m \int_{s_{A}}^{s_{B}} \mathbf{N}^{T}(s) \mathbf{N}(s) d s
$$

The element stiffness matrix $\mathbf{K}^{e}$ and the vector $\mathbf{G}^{e}\left(\mathbf{U}^{e}\right)$, respectively describing linear and nonlinear contributions, are given as:

$$
\begin{aligned}
& \mathbf{K}^{e}=\int_{s_{A}}^{s_{B}}\left[T(s) \mathbf{B}^{T} \mathbf{B}+E A \mathbf{B}^{T} \frac{d \mathbf{x}}{d s} \frac{d \mathbf{x}^{T}}{d s} \mathbf{B}\right] d s \\
& \mathbf{G}^{e}\left(\mathbf{U}^{e}\right)=\int_{s_{A}}^{s_{B}}\left[\frac{1}{2} E A\left\|\mathbf{B} \mathbf{U}^{e}(t)\right\|^{2} \mathbf{B}^{T} \frac{d \mathbf{x}}{d s}+E A \mathbf{B}^{T} \mathbf{B} \mathbf{U}^{e}(t) \mathbf{U}^{e}(t)^{T} \mathbf{B}^{T} \frac{d \mathbf{x}}{d s}+\right. \\
& \\
& \\
&\left.+\frac{1}{2} E A \mathbf{B}^{T} \mathbf{B} \mathbf{U}^{e}(t)\left\|\mathbf{B} \mathbf{U}^{e}(t)\right\|^{2}\right] d s
\end{aligned}
$$

The integral in Eq. (35) is solved as:

$$
\begin{array}{r}
\mathbf{G}^{e}\left(\mathbf{U}^{e}\right)=\frac{1}{2} E A\left(\mathbf{B} \mathbf{U}^{e}(t)\right)^{T}\left(\mathbf{B} \mathbf{U}^{e}(t)\right) \mathbf{B}^{T}(s) \Delta \mathbf{x}_{e}+\operatorname{EAB}^{T} \mathbf{B} \mathbf{U}^{e}(t) \mathbf{U}^{e}(t)^{T} \mathbf{B}^{T} \Delta \mathbf{x}_{e}+ \\
+\frac{1}{2} E A \mathbf{B}^{T} \mathbf{B} \mathbf{U}^{e}(t)\left(\mathbf{B} \mathbf{U}^{e}(t)\right)^{T}\left(\mathbf{B} \mathbf{U}^{e}(t)\right) \Delta s_{e}
\end{array}
$$

with $\Delta \mathbf{x}_{e}=\mathbf{x}\left(s_{B}\right)-\mathbf{x}\left(s_{A}\right)$. This expression contains polynomial quantities of a maximum order equal to three.

The element force vector $\mathbf{F}^{e}(t)=\tilde{\mathbf{F}}^{e}(t)+\mathbf{F}_{\text {ad }}^{e}(t)$ is composed of two contributions:

$$
\begin{aligned}
& \tilde{\mathbf{F}}^{e}(t)=\int_{s_{A}}^{s_{B}} \mathbf{N}^{T}(s) \tilde{\mathbf{f}}(s, t) d s \\
& \mathbf{F}_{\mathbf{a d}}^{e}(t)=\int_{s_{A}}^{s_{B}} \mathbf{N}^{T}(s) \mathbf{f}_{\mathbf{a d}}(s, t) d s
\end{aligned}
$$

Finally the nodal forces vector is: 


$$
\begin{aligned}
& \mathbf{Q}^{e}(t)=\left[\begin{array}{ll}
\mathbf{0} & \mathbf{I}
\end{array}\right]^{T}\left[T\left(s_{B}\right) \mathbf{B} \mathbf{U}^{e}(t)+E A\left(\left.\mathbf{U}^{e}(t)^{T} \mathbf{B}^{T} \frac{d \mathbf{x}}{d s}\right|_{s_{B}}+\frac{1}{2}\left\|\mathbf{B} \mathbf{U}^{e}(t)\right\|^{2}\right)\left(\left.\frac{d \mathbf{x}}{d s}\right|_{s_{B}}+\mathbf{B U}^{e}(t)\right)\right] \\
&-\left[\begin{array}{ll}
\mathbf{I} & \mathbf{0}
\end{array}\right]^{T}\left[T\left(s_{A}\right) \mathbf{B} \mathbf{U}^{e}(t)+E A\left(\left.\mathbf{U}^{e}(t)^{T} \mathbf{B}^{T} \frac{d \mathbf{x}}{d s}\right|_{s_{A}}+\frac{1}{2}\left\|\mathbf{B} \mathbf{U}^{e}(t)\right\|^{2}\right)\left(\left.\frac{d \mathbf{x}}{d s}\right|_{s_{A}}+\mathbf{B U}^{e}(t)\right)\right]
\end{aligned}
$$

Through standard assemblage procedures and imposing the boundary conditions of pinned ends at $s=0$ and $s=L$, the global equation of undamped motion is derived as:

$$
\mathbf{M} \ddot{\mathbf{U}}(t)+\mathbf{K} \mathbf{U}(t)+\mathbf{G}(\mathbf{U})=\mathbf{F}(t)
$$

where $\mathbf{U}(t)$ is the vector collecting the nodal displacements with reference to configuration $C_{I I}$.

A structural damping ratio $\zeta$ is considered for all the linear modes; thus, the structural damping matrix is obtained as:

$$
\mathbf{C}_{s t}=\boldsymbol{\Phi}^{-T} \boldsymbol{\Xi} \boldsymbol{\Phi}^{-1}
$$

where $\boldsymbol{\Xi}$ is a diagonal matrix with elements $2 \zeta \omega_{i}, \omega_{i}$ are natural circular frequencies and $\boldsymbol{\Phi}$ is the modal matrix. The aerodynamic damping given by Eq. (19) leads to a distributed force $\mathbf{f}_{\text {ad }}(s, t)$, which can be rewritten as follows:

$$
\mathbf{f}_{\mathbf{a d}}(s, t)=-\mathbf{D}(s) \dot{\mathbf{u}}(s, t)
$$

where:

$$
\mathbf{D}(s)=-\frac{1}{2} \rho c_{D} b \bar{v}(s) \gamma(s)\left[\mathbf{I}+\mathbf{j}(s) \mathbf{j}^{T}(s)\right] \boldsymbol{\Gamma}(s)
$$

Thus, by Eq.(28) and Eq. (38), the elemental aerodynamic damping force is:

$$
\mathbf{F}_{a d}^{e}(t)=-\left(\int_{s_{A}}^{s_{B}} \mathbf{N}^{T}(s) \mathbf{D}(s) \mathbf{N}(s) d s\right) \dot{\mathbf{U}}^{e}(t)=-\mathbf{C}_{a d}^{e} \dot{\mathbf{U}}^{e}(t)
$$

By standard assemblage procedures:

$$
\mathbf{F}_{a d}(t)=-\mathbf{C}_{a d} \dot{\mathbf{U}}(t)
$$

where $\mathbf{C}_{a d}$ is the assembled aerodynamic damping matrix. The total damping matrix is:

$$
\mathbf{C}=\mathbf{C}_{s t}+\mathbf{C}_{a d}
$$


and the damped equation of motion is finally written as:

$$
\mathbf{M} \ddot{\mathbf{U}}(t)+\mathbf{C} \dot{\mathbf{U}}(t)+\mathbf{K U}(t)+\mathbf{G}(\mathbf{U})=\tilde{\mathbf{F}}(t)
$$

The nodal turbulent wind force $\tilde{\mathbf{F}}(t)$ is assembled starting from the turbulent wind force $\tilde{\mathbf{f}}(s, t)$ according to Eq. (37).

Introducing the coordinate transformation $\mathbf{U}(t)=\mathbf{\Phi q}(t)$, by means of standard modal analysis, the modal equation of motion is derived:

$\ddot{\mathbf{q}}(t)+\Xi \dot{\mathbf{q}}(t)+\mathbf{\Omega}^{2} \mathbf{q}(t)+\mathbf{H}[\mathbf{q}(t)]=\mathbf{Z}(t)$

where, imposing $\boldsymbol{\Phi}^{\top} \mathbf{M} \boldsymbol{\Phi}=\mathbf{I}$, the following quantities are defined: $\boldsymbol{\Xi}=\boldsymbol{\Phi}^{\top} \mathbf{C} \boldsymbol{\Phi}, \boldsymbol{\Omega}^{2}=\boldsymbol{\Phi}^{\top} \mathbf{K \Phi}$, $\mathbf{H}[\mathbf{q}(t)]=\boldsymbol{\Phi}^{T} \mathbf{G}[\boldsymbol{\Phi} \mathbf{q}(t)], \quad \mathbf{Z}(t)=\boldsymbol{\Phi}^{\top} \tilde{\mathbf{F}}(t)$.

\section{Turbulent wind model}

The complete definition of wind action needs the characterization of the turbulent stochastic process $\tilde{v}(s, t)$, which is supposed horizontally directed with arbitrary angle with the $x_{1}$ axis. The process can be considered a zero mean Gaussian stationary one described in the frequency domain by the Cross Power Spectral Density (CPSD) function. The characterization of CPSD function between different points in space is performed by the definition of the coherence function. The following expression is assumed as coherence function:

$$
\operatorname{Coh}_{\tilde{v}_{i} \tilde{v}_{j}}\left[\mathbf{x}\left(s_{i}\right), \mathbf{x}\left(s_{j}\right), \omega\right]=\exp \left(-\frac{\omega \cdot C_{s} \cdot\left\|\mathbf{x}\left(s_{i}\right)-\mathbf{x}\left(s_{j}\right)\right\|}{\pi\left[\bar{v}\left(s_{i}\right)+\bar{v}\left(s_{j}\right)\right]}\right)
$$

where $C_{s}$ is the exponential decay coefficient, $\omega$ is the circular frequency, $\mathbf{x}\left(s_{i}\right)$ and $\mathbf{x}\left(s_{j}\right)$ the coordinates of nodal points $j$ and $k$ of the finite element mesh. Thus, the continuous PSD function is transformed into a discrete matrix $\mathbf{S}_{\tilde{v} \tilde{v}}(\omega)$, with components related to direction $x_{3}$ defined as follows:

$$
S_{\tilde{v_{i}} \tilde{v}_{j}}\left[\mathbf{x}\left(s_{i}\right), \mathbf{x}\left(s_{j}\right), \omega\right]=\sqrt{S_{\tilde{v}_{i} \tilde{v}_{i}}(\omega) S_{\tilde{\tilde{r}_{j}} \tilde{v}_{j}}(\omega)} \operatorname{Coh}_{\tilde{v}_{i} \tilde{r}_{j}}\left[\mathbf{x}\left(s_{i}\right), \mathbf{x}\left(s_{j}\right), \omega\right]
$$


in which $S_{\tilde{v}_{i} \tilde{v}_{i}}\left(s_{i}, \omega\right)$ is the one-sided PSD of turbulent component of wind velocity. In this paper the following PSD has been employed [28]:

$$
S_{\tilde{v}_{j} \tilde{j}_{j}}\left(s_{j}, \omega\right)=\frac{1}{4 \pi} \frac{\delta L_{\tilde{v}}\left(h_{j}\right) \bar{v}\left(s_{j}\right)}{\left[1+1.5 \delta \frac{\omega}{2 \pi} \frac{L_{\tilde{v}}\left(h_{j}\right)}{\bar{v}\left(s_{j}\right)}\right]^{5 / 3}} I_{\tilde{v}}^{2}\left(h_{j}\right)
$$

where $\delta=6.868, L_{\tilde{v}}(h)=300(h / 300)^{\varepsilon}, \varepsilon$ depends on the ground roughness, $I_{\tilde{v}}(h)=1 / \ln \left(h / l_{r}\right)$, and $l_{r}$ is the roughness length. Said $H$ the height above ground level of the origin, $h_{j}=H-x_{2}\left(s_{j}\right)$. For each cable nodal point, at abscissa $s_{j}$, a three-dimensional matrix $\mathbf{S}_{\tilde{\mathbf{v}} \tilde{\mathbf{v}}}\left(s_{j}, \omega\right)$ has been defined as follows:

$$
\mathbf{S}_{\tilde{\mathbf{v}}_{j} \tilde{v}_{j}}\left(s_{j}, \omega\right)=S_{\tilde{v}_{j} \tilde{v}_{j}}\left(s_{j}, \omega\right) \mathbf{k} \mathbf{k}^{T}
$$

Projecting on the plane of the cross section:

$$
\mathbf{S}_{\tilde{\mathbf{w}}_{j} \tilde{\mathbf{w}}_{j}}\left(s_{j}, \omega\right)=S_{\tilde{v}_{j} \tilde{v}_{j}}\left(s_{j}, \omega\right) \gamma\left(s_{j}\right)^{2} \mathbf{j}\left(s_{j}\right) \mathbf{j}\left(s_{j}\right)^{T}
$$

If the cable is divided into $\mathrm{N}$ finite elements, the internal nodal points are $\mathrm{N}-1$ and the global matrix $\mathbf{S}_{\tilde{\mathbf{w}} \tilde{\mathbf{w}}}(\omega)$ with dimension 3(N-1) can be obtained by assemblage of contributes given by Eq. (53). The POD is resorted to reduce computational effort in numerical simulation, choosing the following PSD matrix [23]:

$\mathbf{S}_{\tilde{\mathbf{w}} \tilde{\mathbf{w}}}(\omega)=\boldsymbol{\Psi}(\omega) \boldsymbol{\Lambda}(\omega) \boldsymbol{\Psi}^{*}(\omega)$

where the eigenvectors $\boldsymbol{\Psi}(\omega)$ and eigenvalues $\boldsymbol{\Lambda}(\omega)$ of the PSD matrix have been introduced. The star denotes the transpose of the complex conjugate matrix; indeed, in a general case $\mathbf{S}_{\tilde{\mathbf{w}} \tilde{\mathbf{w}}}(\omega)$ is hermitian and eigenvectors could be complex; however, in our case the PSD matrix is a symmetric and real one. Say $\mathbf{X}$ the diagonal matrix with elements $\rho c_{D} b \Delta s_{e} \bar{w}\left(s_{i}\right)$, the PSD of wind forces can be defined through the following matrix equation:

$$
\mathbf{S}_{\tilde{\mathbf{F}} \tilde{\mathbf{F}}}(\omega)=\mathbf{X} \mathbf{S}_{\tilde{\mathbf{w}} \tilde{\mathbf{W}}}(\omega) \mathbf{X}
$$

By substitution of Eq. (54) in Eq.(55): 
$\mathbf{S}_{\tilde{\mathbf{F}} \tilde{\mathbf{F}}}(\omega)=\mathbf{X} \boldsymbol{\Psi}(\omega) \boldsymbol{\Lambda}(\omega) \boldsymbol{\Psi}^{*}(\omega) \mathbf{X}$

The PSD matrix of modal forces $\mathbf{Z}(t)$ can be easily derived:

$$
\mathbf{S}_{\mathrm{zz}}(\omega)=\boldsymbol{\Phi}^{T} \mathbf{X} \boldsymbol{\Psi}(\omega) \boldsymbol{\Lambda}(\omega) \boldsymbol{\Psi}^{*}(\omega) \mathbf{X} \boldsymbol{\Phi}
$$

This means that, instead of the classical wind modes [21][22], the ones given by columns of the matrix $\mathbf{X} \Psi(\omega)$ are considered. The product with structural modes $\boldsymbol{\Theta}(\omega)=\Psi^{*}(\omega) \mathbf{X} \boldsymbol{\Phi}$ does not give a diagonal matrix as in the classical case, because out-of-diagonal terms may not be negligible implying that modal forces are not uncoupled in stochastic sense. Finally Eq. (57) can be rewritten as follows:

$$
\mathbf{S}_{\mathrm{ZZ}}(\omega)=\boldsymbol{\Theta}(\omega)^{T} \boldsymbol{\Lambda}(\omega) \boldsymbol{\Theta}(\omega)
$$

The numerical time domain solution is then applied to the cable model. The POD expansion Eq. (58) allows to lower the computational effort of numerical simulation. In fact, the multivariatemulticorrelated process becomes a superposition of multivariate-monocorrelated ones. The PSD of modal forces is used to simulate time histories:

$$
\mathbf{Z}(t)=\sum_{j=1}^{n} \mathbf{r}_{j}(t)
$$

in which $n$ is the number of modes considered in the analysis; $\mathbf{r}_{j}(t)$ is a vector of monovariate processes defined as [29]:

$$
\mathbf{r}_{j}(t)=\sum_{k=1}^{m} 2 \sqrt{\Lambda_{j}\left(\omega_{k}\right) \Delta \omega} \boldsymbol{\Theta}_{j}\left(\omega_{k}\right) \eta_{j k} \cos \left(\omega_{k} t\right)
$$

where $m$ represents the number of subdivisions in frequency; $\Lambda_{j}\left(\omega_{k}\right)$ is the $j$-th element of the diagonal matrix $\boldsymbol{\Lambda}(\omega) ; \boldsymbol{\Theta}_{j}\left(\omega_{k}\right)$ is the $j$-th column vector of the matrix $\boldsymbol{\Theta}(\omega) ; \eta_{j k}$ are normal distributed complex random numbers with zero mean and unitary standard deviation. The time integration in the modal space, Eq.(48), can be performed by means of R unge-K utta method. 


\section{Applications}

Four cable layouts, depicted in Figure 3, have been considered in the applications. The first two are related to cables with supports at the same level, the others regard cables with different level of the supports. The cable section and mass per unit length are the same for all the examples and are representative of an ACSR cable for high voltage conductors, which is very sensitive to wind turbulence [30]. The geometrical and mechanical properties of the cables are resumed in Table 1. All the cables are characterized by Irvine's parameters $\lambda^{2}$ falling over the first crossover point. Cable 1 has the smallest sag, Cable 2 is characterized by a larger value of sag-to-span ratio; both cables have leveled supports (horizontal cables). Cable 3 and Cable 4 are inclined with an angle $\vartheta=30^{\circ}$ (see Fig. 3). The first three cables are subjected to a wind load with $\varphi=\pi / 2$, whereas for Cable 4 it is chosen $\varphi=\pi / 4 . \ln$ Table $1, d_{H}$ and $d_{V}$, respectively are the horizontal and vertical distance between supports and $b$ is the cable diameter.

M ean and turbulent wind are defined by the following parameters: $u_{*}=0.8 \mathrm{~m} / \mathrm{s}, \kappa=0.4$, $l_{r}=0.01 \mathrm{~m}, C_{s}=10, \rho=1.25 \mathrm{Kg} / \mathrm{m}^{3}, \varepsilon=0.13$. The height $H$ above ground of first cable end is placed at $40 \mathrm{~m}$ for the first two cables, at $120 \mathrm{~m}$ for the third and fourth cables. According to Eq. (25), for the two values of $H$ a mean velocity $\bar{v}=16.59 \mathrm{~m} / \mathrm{sec}$ and $\bar{v}=18.79 \mathrm{~m} / \mathrm{sec}$ are obtained. The drag coefficient of the cables is $c_{D}=1.2$. For the sake of the example, it has been adopted a structural damping ratio equal to 0.005 for all modes.

In all the analyses the circular frequency step is $\Delta \omega=0.003 \mathrm{rad} / \mathrm{sec}$ and the time step is $\Delta t=0.04 \mathrm{sec}, 10$ modal shapes and modal forces have been considered and cables have been divided into 50 finite elements.

Figures 4 show the components of mean wind velocities along the cables at the equilibrium configuration $C_{I I}$. As expected, for horizontal cables under orthogonal wind, the longitudinal component is anti-symmetric, whereas the vertical and the along wind components are symmetric. 
In the case of inclined cables, no symmetry or anti-symmetry is encountered. As the velocities determine pressure loads on the cable, this aspect outlines a different loading with respect to classic approaches. The latter are based on continuous modal analysis, where modal shapes and frequencies are evaluated in closed form with reference to equilibrium configuration $C_{I}$. The refined mean wind load derived by the proposed approach can differ significantly in the case of sagged or inclined cables. On the other hand, for very taut horizontal cables the classic approach is appropriate. In addition, the components of mean wind forces show that for horizontal cables the configuration $C_{I I}$ is planar, for inclined cables this is not the case. Thus, this situation can be only roughly described by the classical models.

The comparison of modes with those derived by a classical small-sag formulation which neglects longitudinal inertia forces and condenses longitudinal modes, highlights the differences with the proposed procedure.

The first five modal shapes are depicted in Figure 5, in the global reference system. As the sag increases, the longitudinal component (continuous line) of some modes becomes relevant, whereas in inclined cables is is always significant. It is worth noting that the two inclined cables, which differ between each others only for the wind direction, possess different modes and frequencies; these differences becomes more and more relevant for higher order modes.

In order to compare the modes with those derived by the classical approach, these are depicted in Figure 6, for the horizontal cables, in a rotated reference system, with axes $\xi_{1}$ and $\xi_{2}$ laying on the plane assumed by the cable under mean wind. The figure shows that the first five modes of $\mathrm{Cable} 1$, the taut one, are very close to those pertinent to a classical analysis on the other hand some differences appear for Cable 2, the sagged one. Table 2 lists for Cable 2 frequencies obtained by static condensation of the longitudinal degree of freedom and those given by the proposed method. The comparison evidences that for large sagged and inclined cables the classic analysis may be inappropriate. 
N onlinear dynamic analysis has been performed by making use of the R unge-K utta method, numerically solving Eq. (48). The modal forces $\mathbf{Z}(t)$ have been simulated by means of Eq. (59) and (60), using the full PSD matrix defined in Eq. (58). The projection on the $\left(x_{2}, x_{3}\right)$ plane, reported in Figure 7, for Cable 1 resembles an arc of circumference because it behaves similarly to a rigid body rotating around axis $x_{1}$. In the figure, the origin represents the static configuration due to weight and mean wind.

The standard deviation, skewness and kurtosis of the three components of displacements at cable midpoint have been calculated and reported in Table 4, supposing the response as a stationary process, by simulating nine time histories of $1000 \mathrm{sec}$ each. The resulting probability density function (pdf) are plotted in Figures 8-10 along with their G aussian approximation. The inadequacy of the Gaussian assumption is evident for Cables 2-4. Note that Cables 2-4 have sub-kurtotic pdf, as they are more sagged and their dynamic behaviour is close to inextensible cables with bounded response so that non linear effects are magnified.

Finally the 0.05 and 0.95 fractiles of the tension along the cable are plotted in Figure 11 and compared with the static value at configuration $C_{I I}$. The 0.05 fractile is smaller than the static value only for Cable 1, whereas in the other cases it results to be larger. It is interesting to emphasize that the dynamic effect on cable tension is much more pronounced when sag increases (Cables 2-4). In the inclined cables, a predictable asymmetry is evident.

\section{Conclusions}

The non-linear dynamic response of a cable under turbulent wind has been considered. The dynamic equilibrium is evaluated with reference to the actual initial equilibrium configuration; that is, the static configuration under self weight and mean wind which is attained by an iterative procedure starting from the static equilibrium configuration under self weight only. The proposed 
procedure allows arbitrary wind direction and accounts for longitudinal inertia forces so to model general problems such as arbitrarily sagged cables and cables with supports at different height. The initial equilibrium configuration is reproduced by a continuous approach based on the catenary equation, whereas non linear motion is described by a non-linear finite element approach. The cable element is defined allowing large strains and displacements, the analysis is performed in a reduced modal space by simulation of wind modal forces adopting a POD expansion.

A pplications to four different cable problems show the versatility of the method and its ability to detect specific behaviour. In particular, strong non Gaussianity has been traced for some displacement components and a remarkable increase of cable tension due to turbulent wind is encountered for sagged cables, emphasizing the risk of fatigue failures in suspended cables.

Further investigations, aimed at a deeper comprehension of dynamics of wind-excited cables, should consider the three dimensionality of turbulent phenomenon and represent a future task for the authors.

\section{Appendix}

The following steps are required by the proposed formulation

1. First of all define the deformed shape of the cable under self weight $\mathbf{x}_{I}\left(s_{0}\right)$, by making use of the classic catenary approach, so to describe configuration $C_{I}$.

2. Evaluate the tangent versor along the cable $\mathbf{t}\left(s_{0}\right)$, with respect to configuration $C_{I}$, and derive through Eqs. (3) and (4) the versor of wind velocity $\mathbf{j}\left(s_{0}\right)$.

3. Define the undisturbed mean wind by Eq. (25).

4. Divide the cable into elements of length $\Delta s_{0}$ so to evaluate the nodal static wind forces by Eq. (20).

5. Numerically solving Eq. (22) a new static configuration of the cable is obtained and, by Eqs. (3) and (4), the related versor $\mathbf{j}\left(s_{0}\right)$. 
6. Repeat the procedure until convergence. Take the final values of $\mathbf{j}(s), T(s), \mathbf{x}(s)$.

7. Divide the cable into finite elements and evaluate the mass matrix by Eq. (33), the stiffness matrix by Eq. (34), the damping matrix by Eqs. (43)-(46).

8. Define the turbulent wind by Eqs. (49)-(51) and derive the PSD matrix of wind forces at nodal points by Eqs. (53)-(56).

9. Project the equation of motion in the modal space and evaluate the PSD matrix of modal forces by Eq. (57)-(58).

10. Simulate modal forces through Eq. (60).

11. Solve numerically the equation of motion (48), updating at each step the nonlinear term $\mathbf{H}[\mathbf{q}(t)]$, dependent upon Eq. (36).

\section{References}

[1] H.M . Irvine. Cable structures. The M IT Press, Cambridge, 1981.

[2] Impollonia N., Ricciardi G., Saitta F., Statics of Elastic Cables under 3D Point Forces, International Journal of Solids and Structures (In press), doi:10.1016/j.ijsolstr.2011.01.007.

[3] H.M. Irvine, T.K. Caughey, The linear theory of free vibration of a suspended cable, Proceedings of the Royal Society of London. 341 (1974) 299-315.

[4] A. Luongo, G. Rega, F. Vestroni, Planar nonlinear free vibration of an elastic cable, International Journal of Non-Linear Mechanics, 19 (1984) 39-52.

[5] F. B enedettini, G. Rega, Nonlinear dynamics of an elastic cable under planar excitation. International Journal of Non-Linear Mechanics, 22 (1987) 497-509.

[6] G. Ricciardi, F. Saitta, A continuous vibration analysis model for cables with sag and bending stiffness, Engineering Structures, 30 (2008), 1459-1472.

[7] M.S. Triantafyllou, L. Grinfogel, Natural frequencies and modes of inclined cables, Journal of Structural Engineering, 112 (1986) 139-148.

[8] M. M atsumoto, T. Saitoh, M. Kitazawa, H. Shirato, T. Nishizaki, Response characteristics of rain-wind induced vibration of stay-cables of cable-stayed bridges, Journal of Wind Engineering and Industrial Aerodynamics, 57 (1995) 323-333.

[9] M. M atsumoto, Y. Daito, T. K anamura, Y. Shigemura, S. Sakuma, H. Ishizaki, Wind induced vibration of cables of cable-stayed bridges, Journal of Wind Engineering and Industrial Aerodynamics, $74-76$ (1998) 1015-1027. 
[10]M. Matsumoto, T. Y agi, H. Hatsuda, T. Shima, M. Tanaka, H. Naito, Dry galloping characteristics and its mechanism of inclined/yawed cables, Journal of Wind Engineering and Industrial Aerodynamics, (2010), doi:10.1016/j.jweia.2009.12.001.

[11]X. Liu, B. Y an, H. Zhang, S. Zhou, Nonlinear numerical simulation method for galloping of iced conductor, Applied Mathematics and Mechanics, 30 (2009) 489-501.

[12] N. Impollonia, G. Ricciardi, F. Saitta, Dynamic Behaviour of Stay-Cables with Rotational Dampers, Journal of Engineering mechanics ASCE, 136 (2010).

[13]J.A. Main, N.P. Jones, Evaluation of viscous dampers for stay-cable vibration mitigation, Journal of Bridge Engineering, 6 (2001), 385-397.

[14]D. Zuo, N.P. Jones, W ind tunnel testing of yawed and inclined circular cylinders in the context of field observations of stay-cable vibrations, Journal of Wind Engineering and Industrial Aerodynamics, 97 (2009) 219-227.

[15]Y. Hikami, N. Shiraishi, Rain-wind induced vibrations of cables in cable stayed bridges, Journal of Wind Engineering and Industrial Aerodynamics, 29 (1988) 409-418.

[16]A.M. Loredo-Souza, A.G. Davenport, A novel approach for wind tunnel modelling of transmission lines, Journal of Wind Engineering and Industrial Aerodynamics, 89 (2001) 10171029.

[17] M. Di Paola, G. M uscolino, A. Sofi, M onte Carlo simulation for the response analysis of longspan suspended cables under wind loads, Wind and Structures, 7 (2004) 107-130.

[18] M. Lazzari, A.V. Saetta, R.V. Vitalini, Non-linear dynamic analysis of cable-suspended structures subjected to wind actions, Computers \& Structures, 79 (2001) 953-969.

[19] V. Gattulli, L. M artinelli, F. Perotti, F. Vestroni, Dynamics of suspended cables under turbulence loading: Reduced models of wind field and mechanical system, Journal of Wind Engineering and Industrial Aerodynamics, 95 (2007) 183-207.

[20] M. Shinozuka, Simulation of multivariate and multidimensional random processes, Journal of Acoustic Society of America, 49 (1970), 357-368.

[21]M. Di Paola, I. Gullo, Digital generation of multivariate wind field processes, Probabilistic Engineering Mechanics, 16 (2001), 1-10.

[22] L. Carassale, G. Solari. Wind modes for structural dynamics: a continuous approach, Probabilistic Engineering Mechanics, 17 (2002) 157-166.

[23]X. Chen, A. Kareem, Proper Orthogonal Decomposition-Based Modeling, A nalysis, and Simulation of Dynamic Wind L oad Effects on Structures, Journal of Engineering Mechanics, 131 (2005), 325-339.

[24] L. Carassale, G. Piccardo, Nonlinear discrete models for the stochastic analysis of cables in turbulent wind, International Journal of Non-Linear Mechanics, 45 (2010) 219-231. 
[25]].H.G. Macdonald, G.L. Larose, A unified approach to aerodynamic damping and drag/lift instabilities, and its application to dry inclined cable galloping, Journal of Fluids and Structures, 22 (2006) 229-252.

[26] E. Simiu, R.H. Scanlan, Wind Effects on Structures. Fundamentals and Applications to Design, John Wiley \& Sons, New Y ork, 1996.

[27]F. Saitta, M odels and A pplications for Statics and Dynamics of Cables, PhD thesis, University of M essina, Italy (2009).

[28] G. Solari, G. Piccardo, Probabilistic 3-D turbulence modeling for gust buffeting of structures, Probabilistic Engineering M echanics, 16 (2001), 73-86.

[29] G. M uscolino, Dinamica delle strutture, M cGraw-Hill, M ilan, 2002 (in Italian).

[30]S. Karabay, F.K. Önder, An approach for analysis in refurbishment of existing conventional HV -A CSR transmission lines with A A A C, Electric Power Systems Research, 72 (2004), 179-185.

\section{Table Captions}

Table 1. Properties of the cables.

Table 2. Circular frequencies of Cable 2

Table 3. Response statistics at $\mathrm{s}=\mathrm{L} / 2$ for $2.2510^{5}$ sampling points.

\section{Figure Captions}

Figure 1. Cable configurations.

Figure 2. Effective wind velocity vector $\mathbf{w}$.

Figure 3. Sketches of the cables analyzed in the applications.

Figure 4. M ean wind components at static equilibrium $C_{I I}$.

Figure 5. First five modes and frequencies of the cables: $x_{1}$ component by continuous line, $x_{2}$ component by dashed line, $x_{3}$ component by dot-dashed line. 
Figure 6. First five modes of Cables 1 and 2 in a rotated frame, with axes $\xi_{1}$ and $\xi_{2}$ laying on the plane of the cable plane in the static configuration: Iongitudinal component $\xi_{1}$ by continuous line, $\xi_{2}$ component by dashed line, out of plane component $\xi_{3}$ by dot-dashed line.

Figure 7. Projection on the $\left(x_{2}, x_{3}\right)$ plane of displacement at $s=L / 2$.

Figure 8. Probability density function of displacement along $x_{1}$ at $s=L / 2$ (symbols) and Gaussian approximation (continuous line).

Figure 9. Probability density function of displacement along $x_{2}$ at $s=L / 2$ (symbols) and Gaussian approximation (continuous line).

Figure 10. Probability density function of displacement along $x_{3}$ at $s=L / 2$ (symbols) and Gaussian approximation (continuous line).

Figure 11. Tension along the cable: static value under self weight and mean wind (continuous line); 0.95 fractile $(+)$ and 0.05 fractile $(x)$ under turbulent wind .

\section{Research Highlights}

A non-linear FE model of inclined cables is proposed for dynamic response under wind.

The procedure allows arbitrary wind direction and accounts for longitudinal inertia forces. A remarkable increase of cable tension due to turbulent wind is evidenced for sagged cables. 


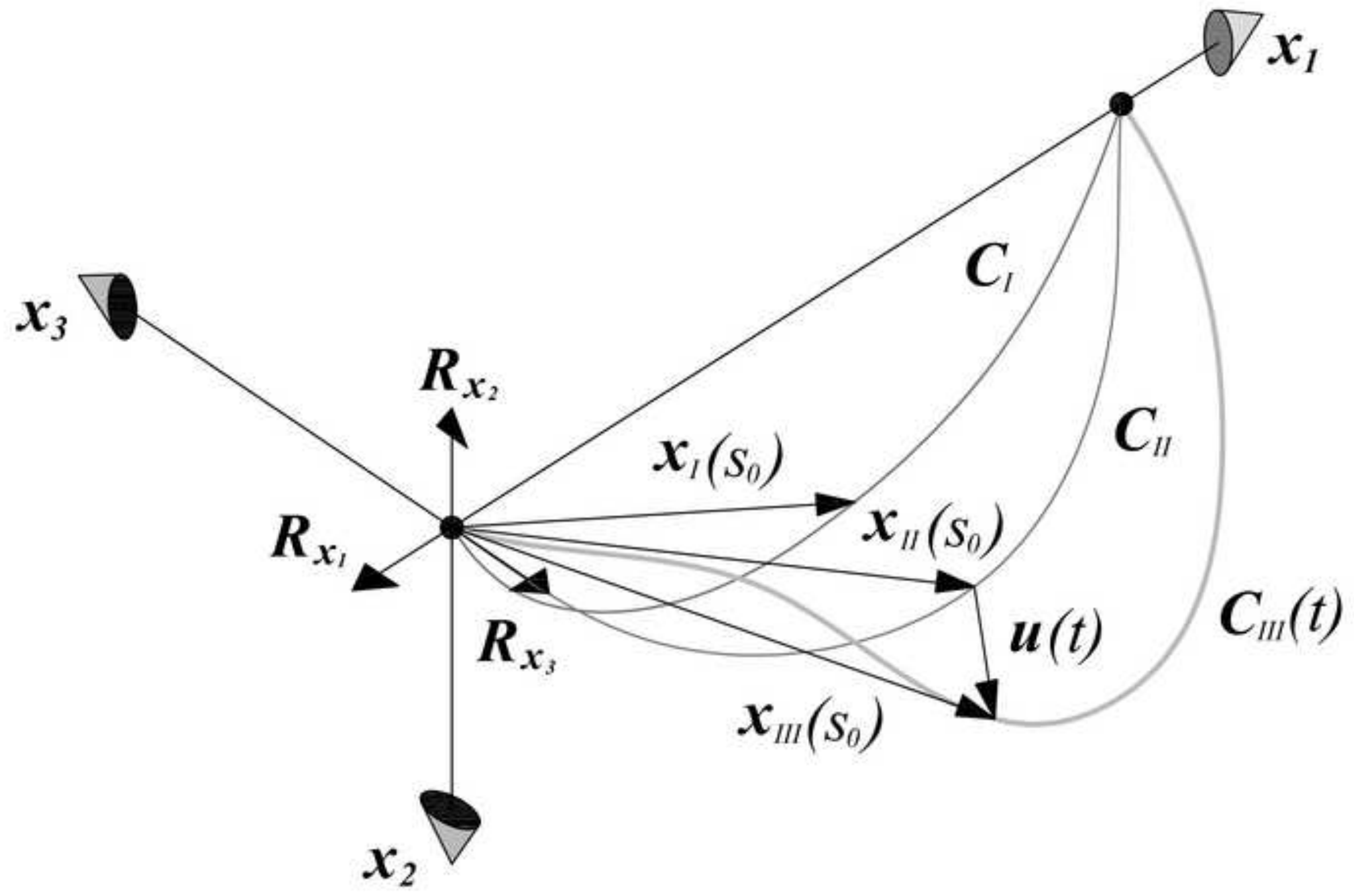




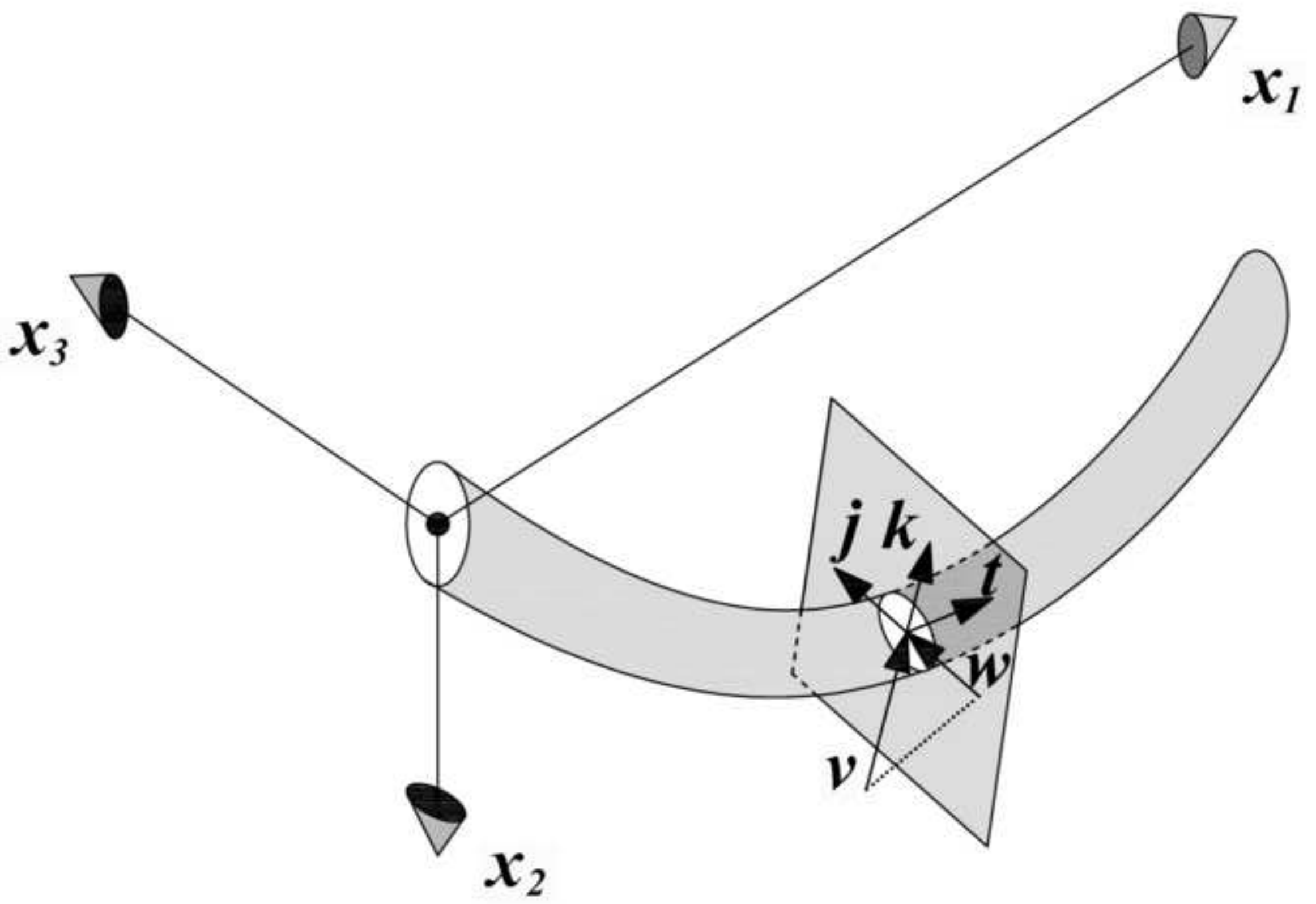



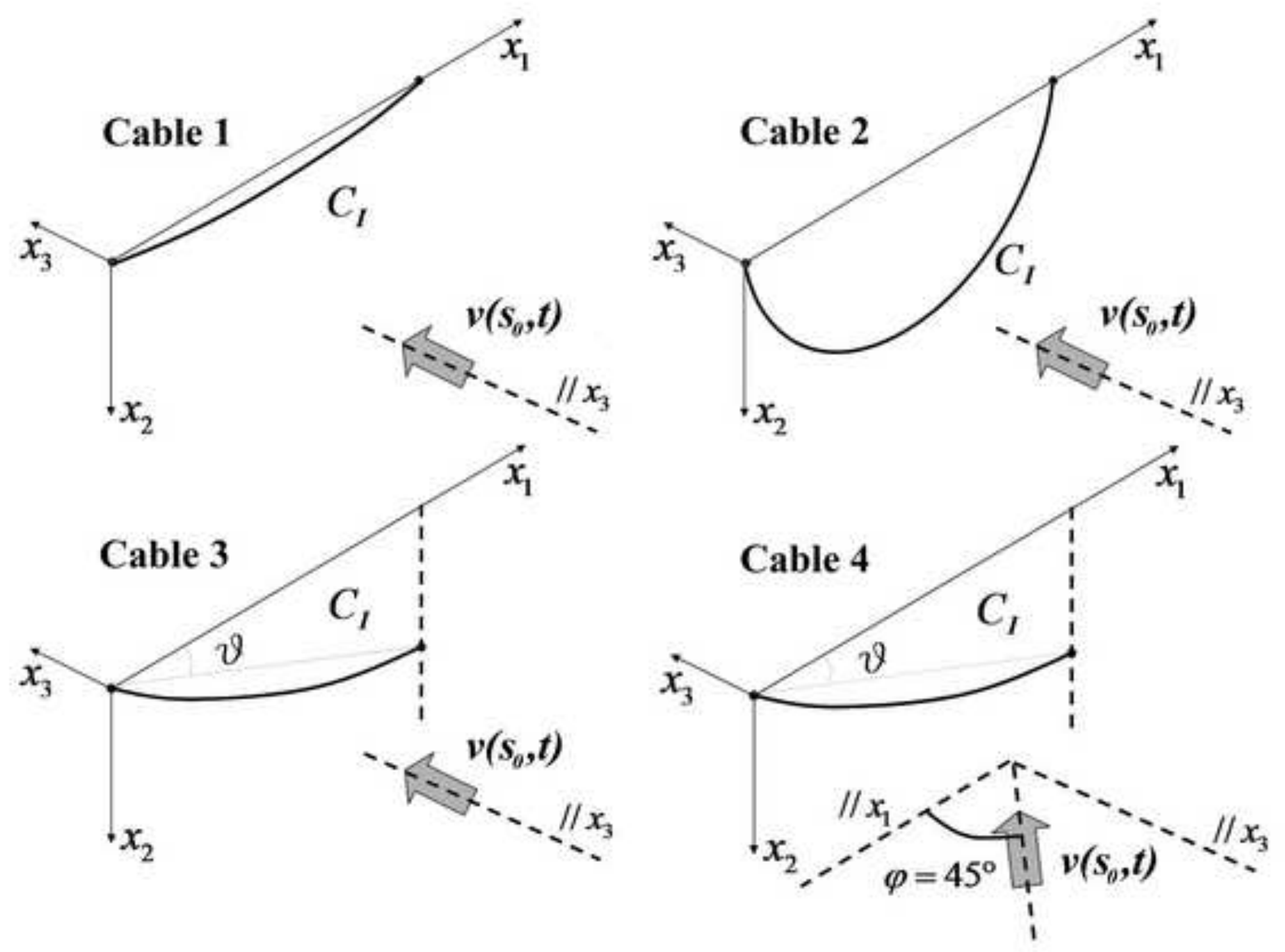

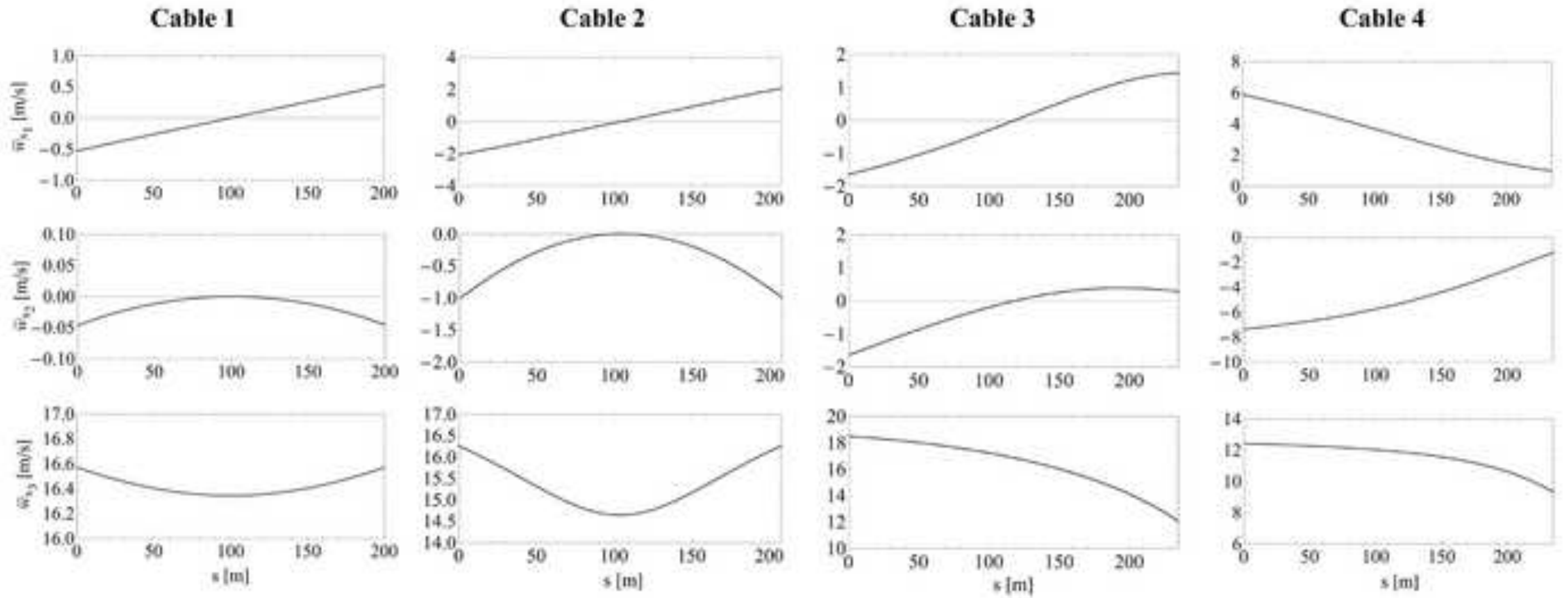
Cable 1
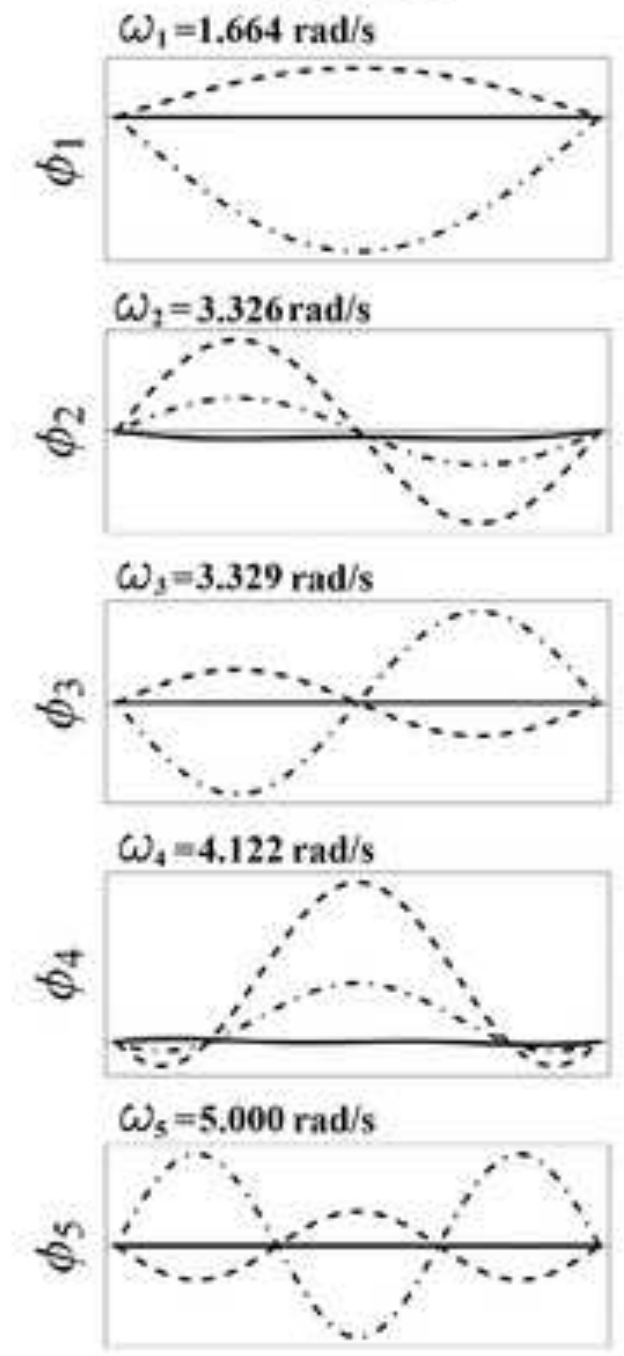

Cable 2
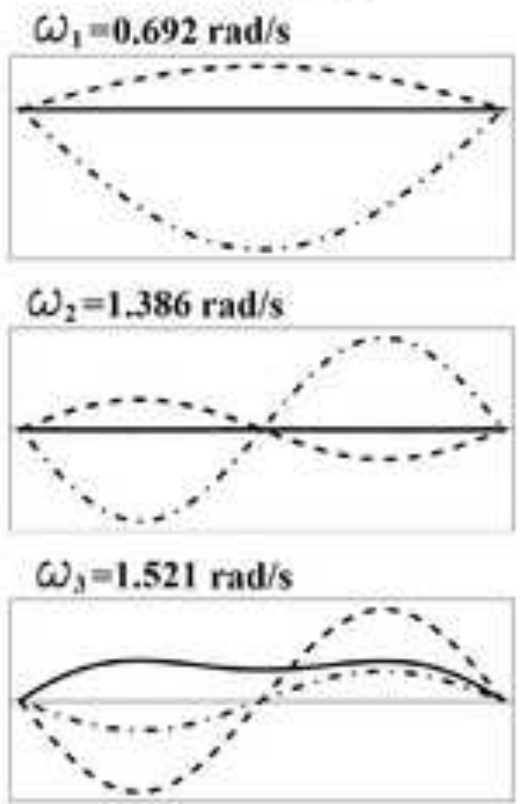

$\omega_{4}=2.081 \mathrm{rad} / \mathrm{s}$

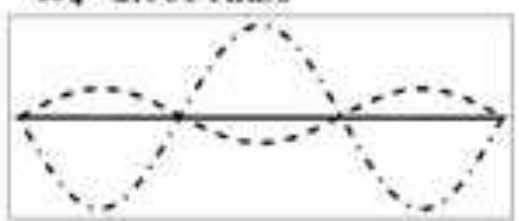

$\omega_{\mathrm{s}}=2.294 \mathrm{rad} / \mathrm{s}$

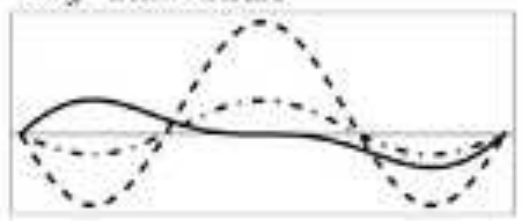

Cable 3

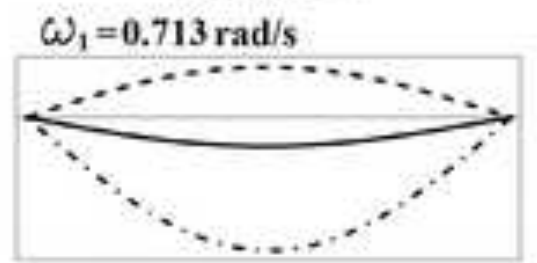

$\omega_{2}=1.426 \mathrm{rad} / \mathrm{s}$
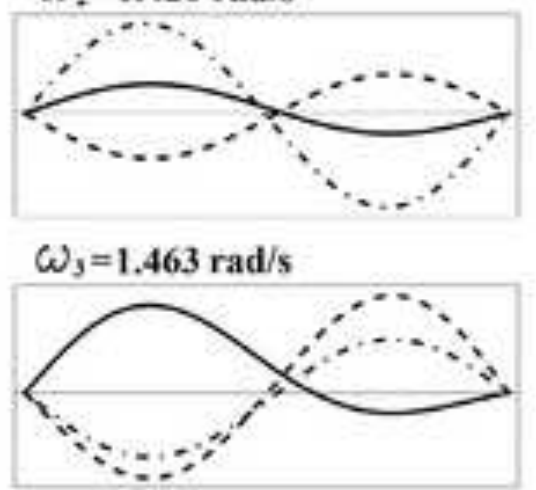

$\omega_{4}=2.143 \mathrm{rad} / \mathrm{s}$

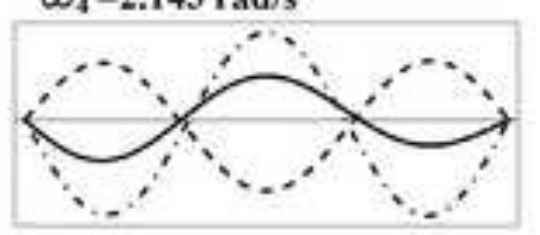

$\omega_{s}=2.154 \mathrm{rad} / \mathrm{s}$

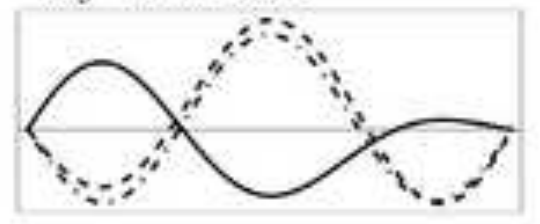

Cable 4
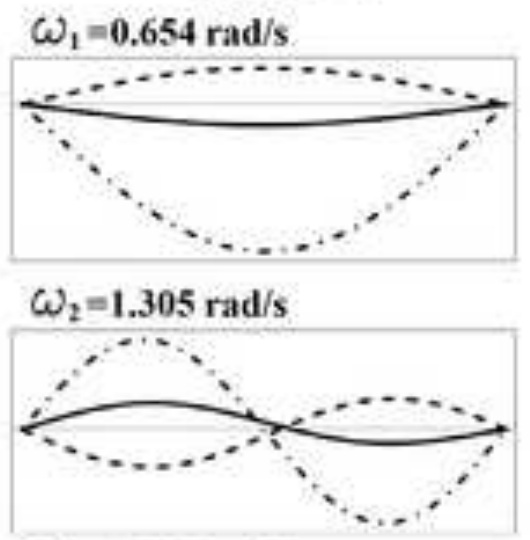

$\omega_{3}=1.338 \mathrm{rad} / \mathrm{s}$

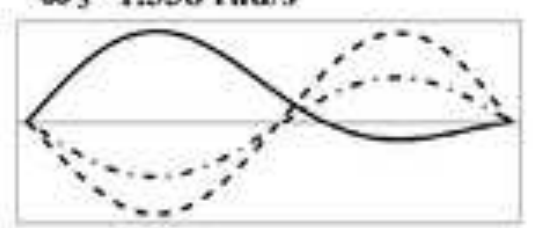

$\omega_{4}=1.962 \mathrm{rad} / \mathrm{s}$

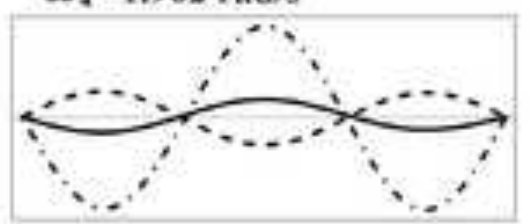

$\omega_{s}=1.991 \mathrm{rad} / \mathrm{s}$

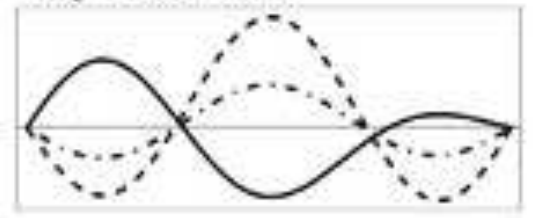


Cable 1
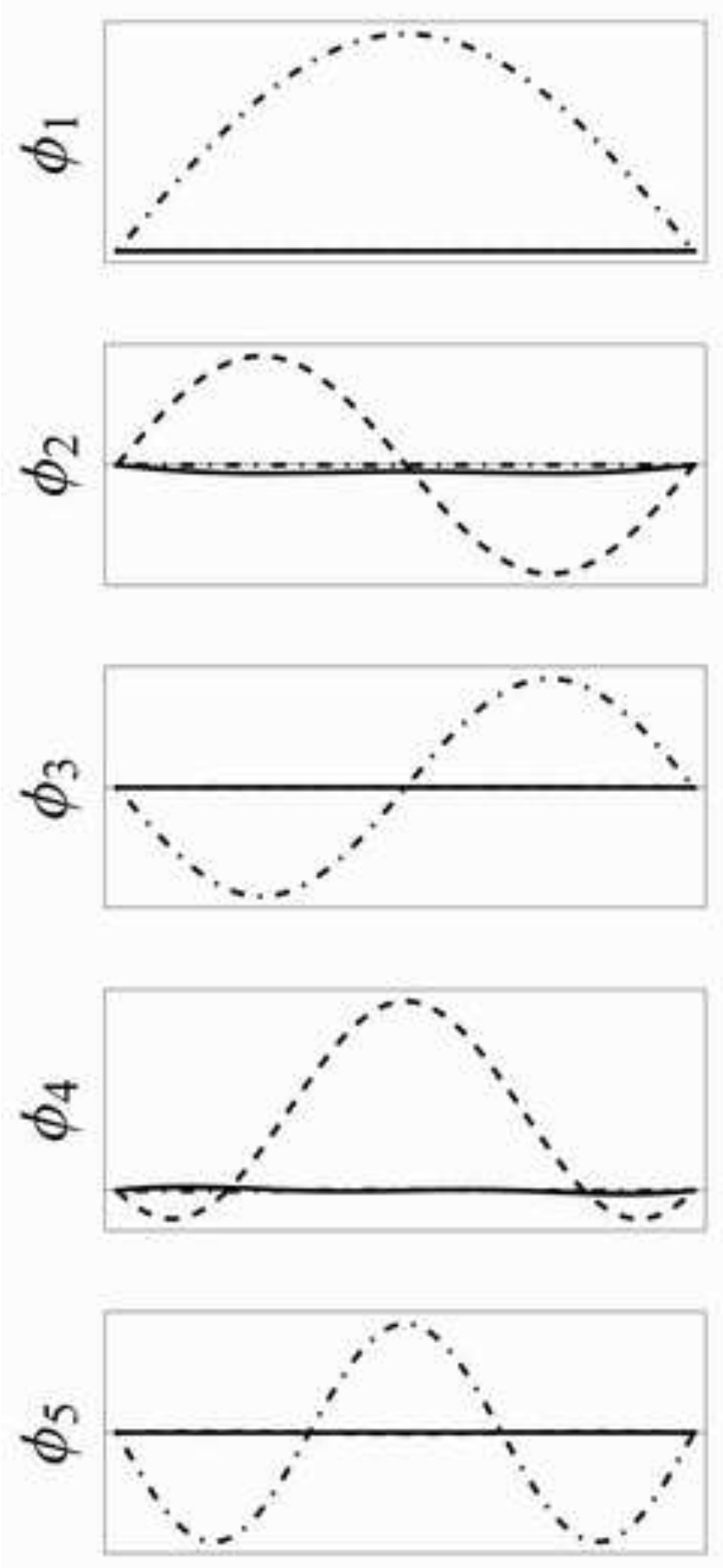

Cable 2
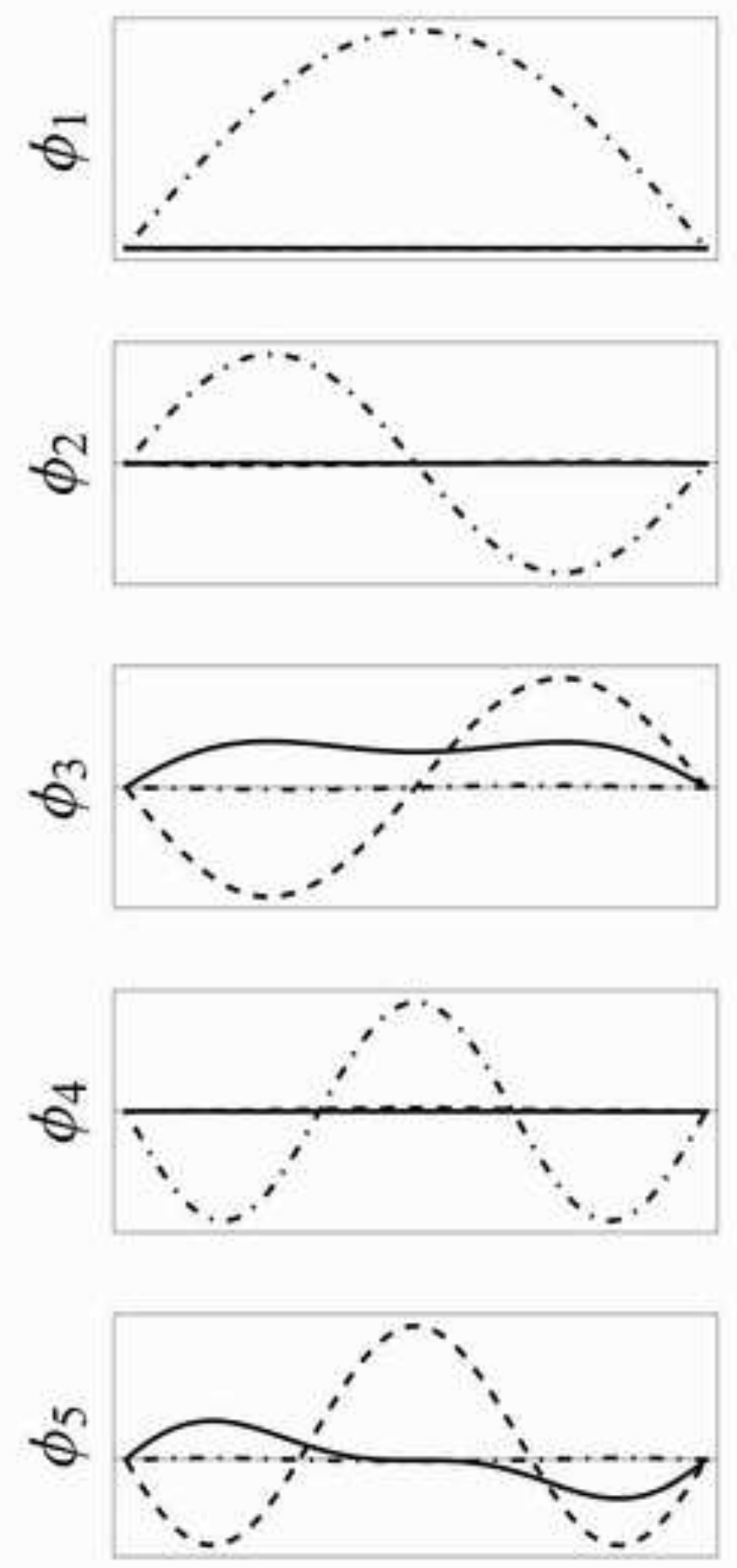 \\ ACGEPTED MANUSCRIPI}




\section{Cable 1}

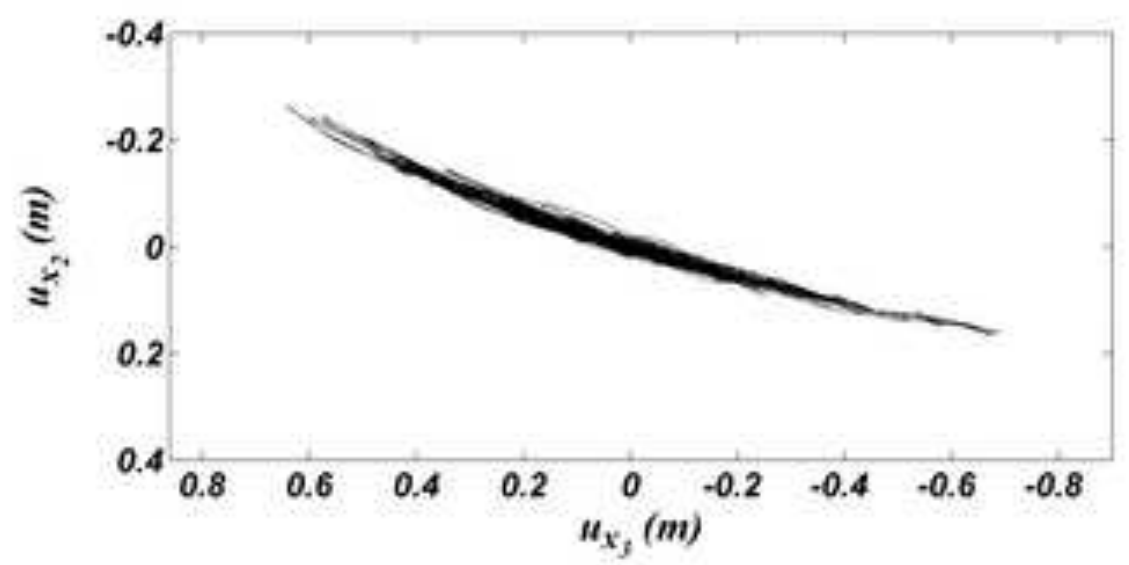

Cable 3

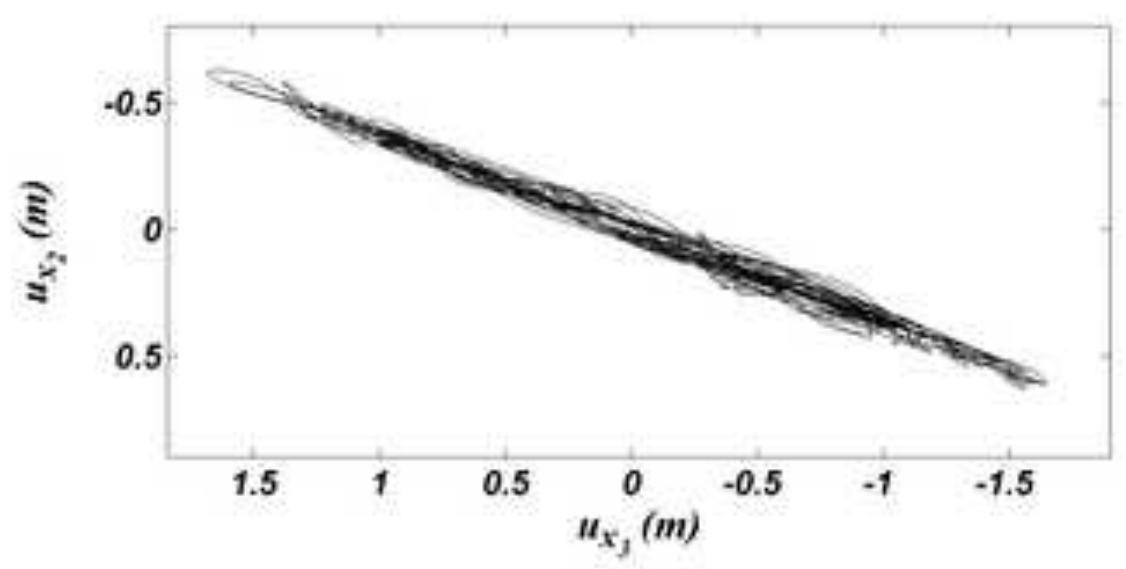

\section{Cable 2}

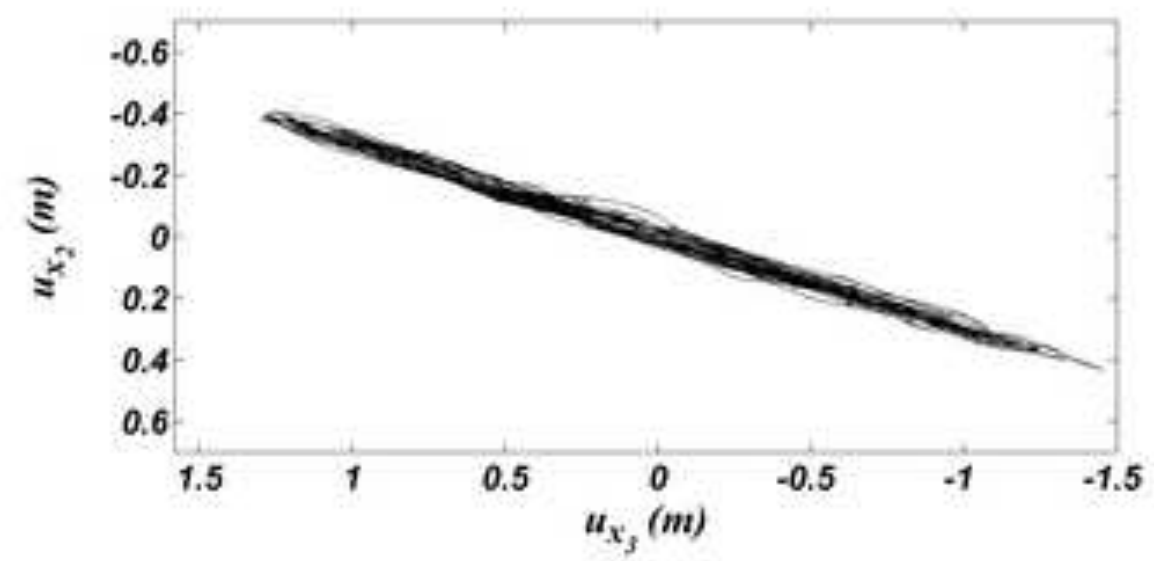

Cable 4

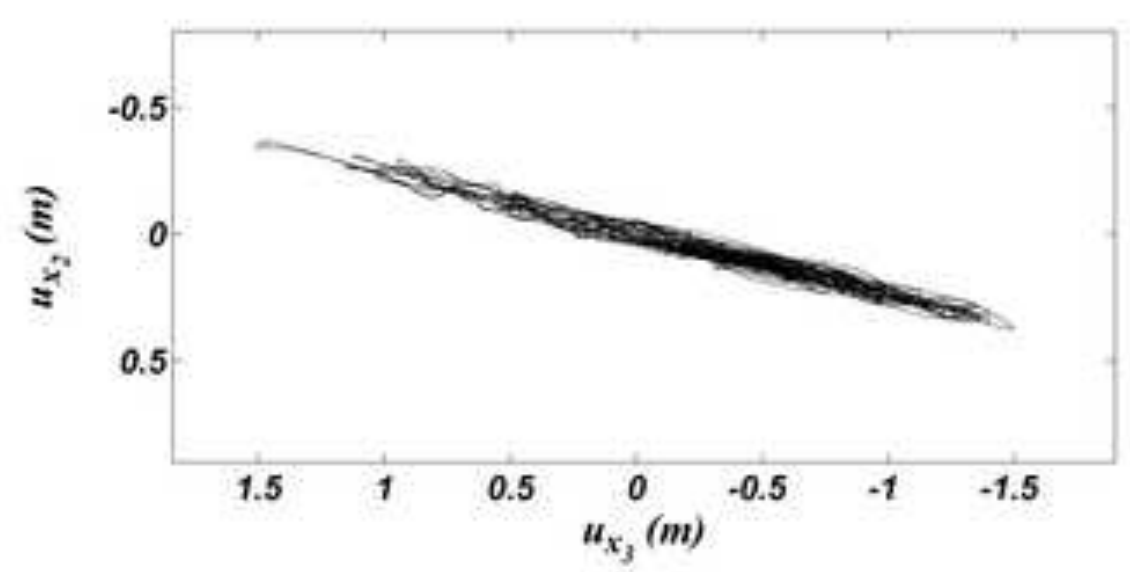


Cable 1

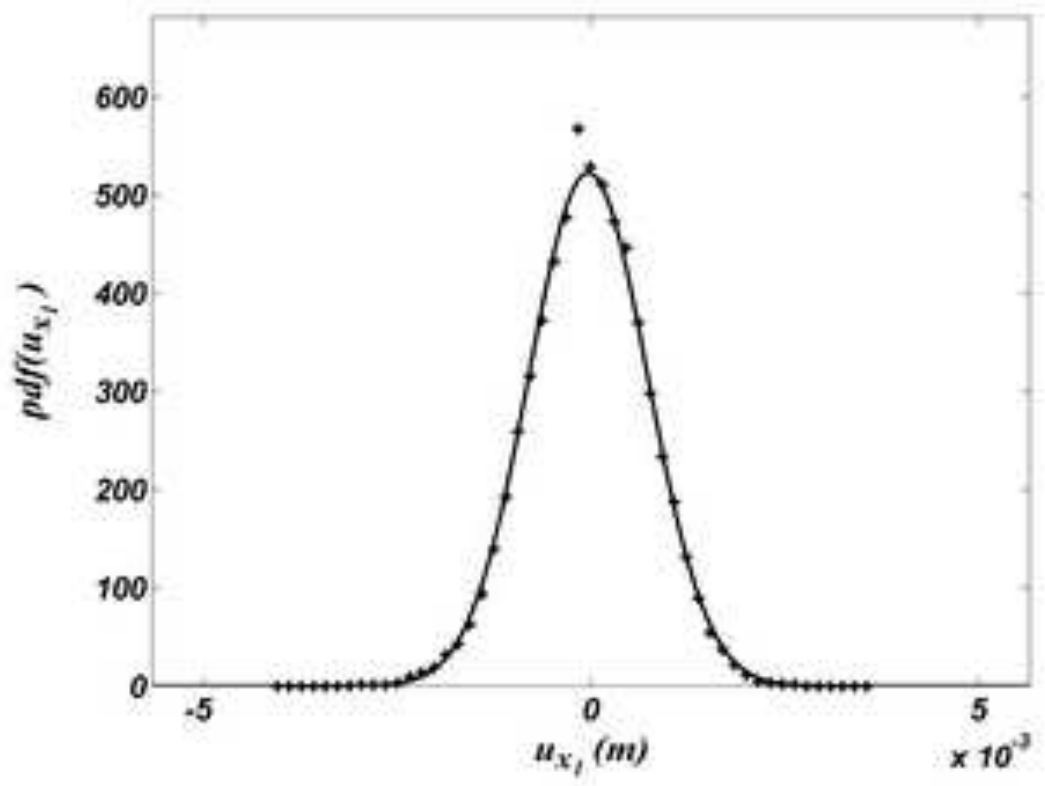

Cable 3

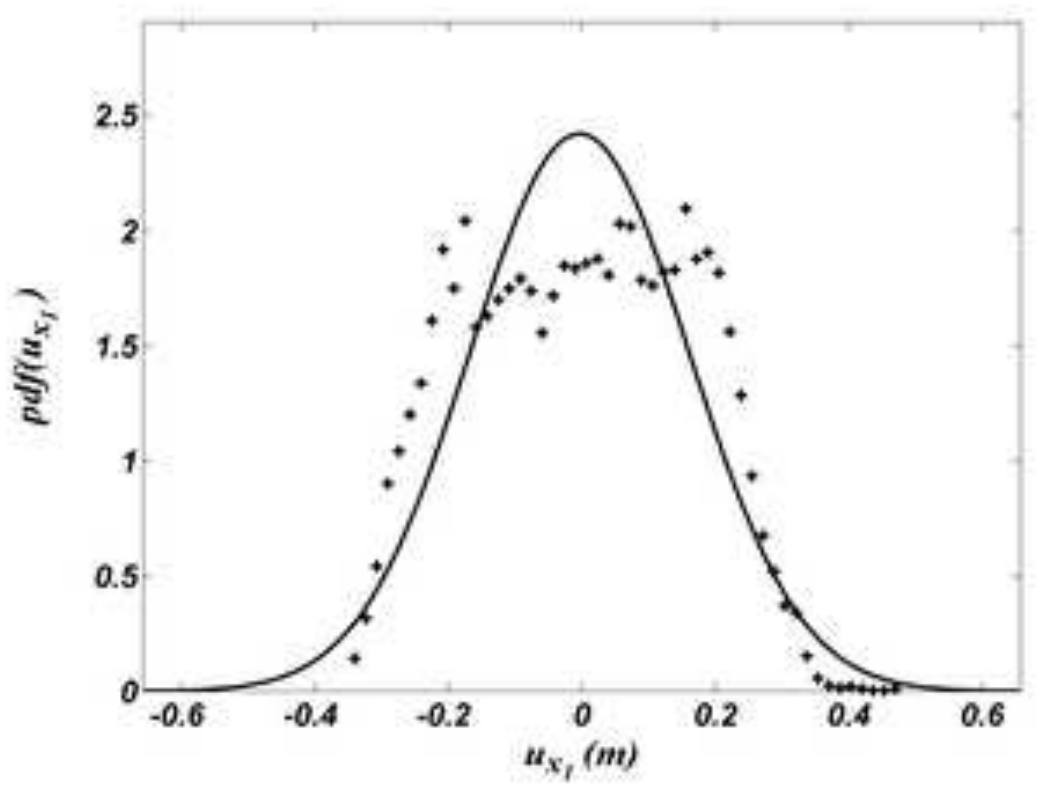

Cable 2

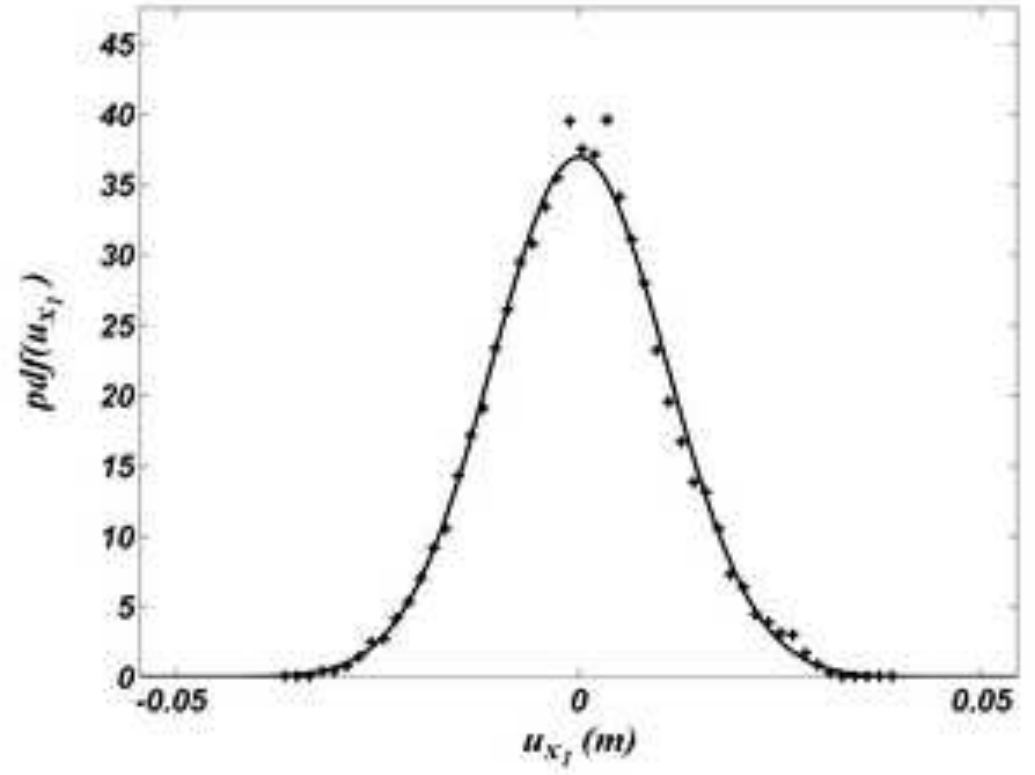

Cable 4

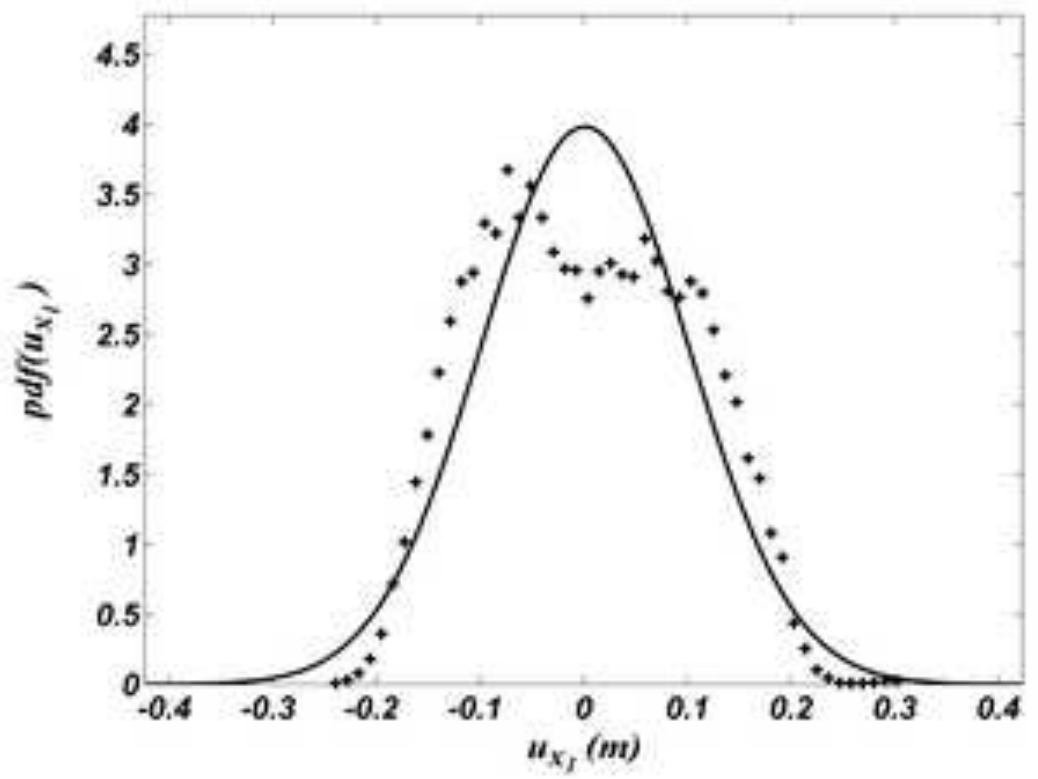


Cable 1

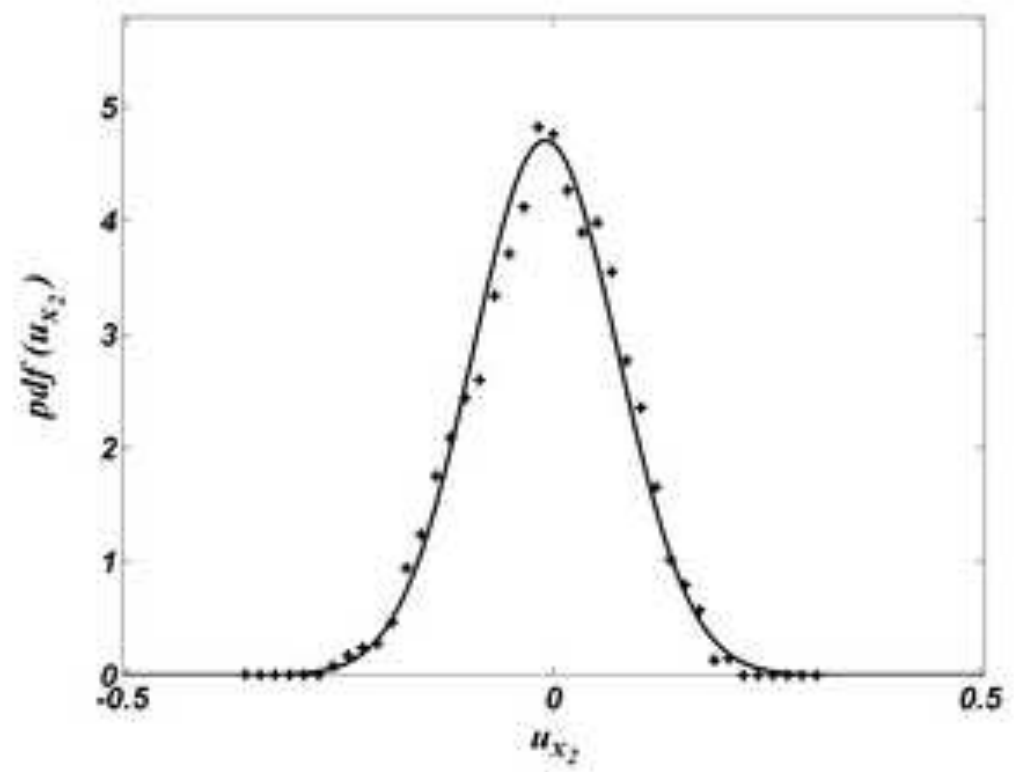

Cable 3

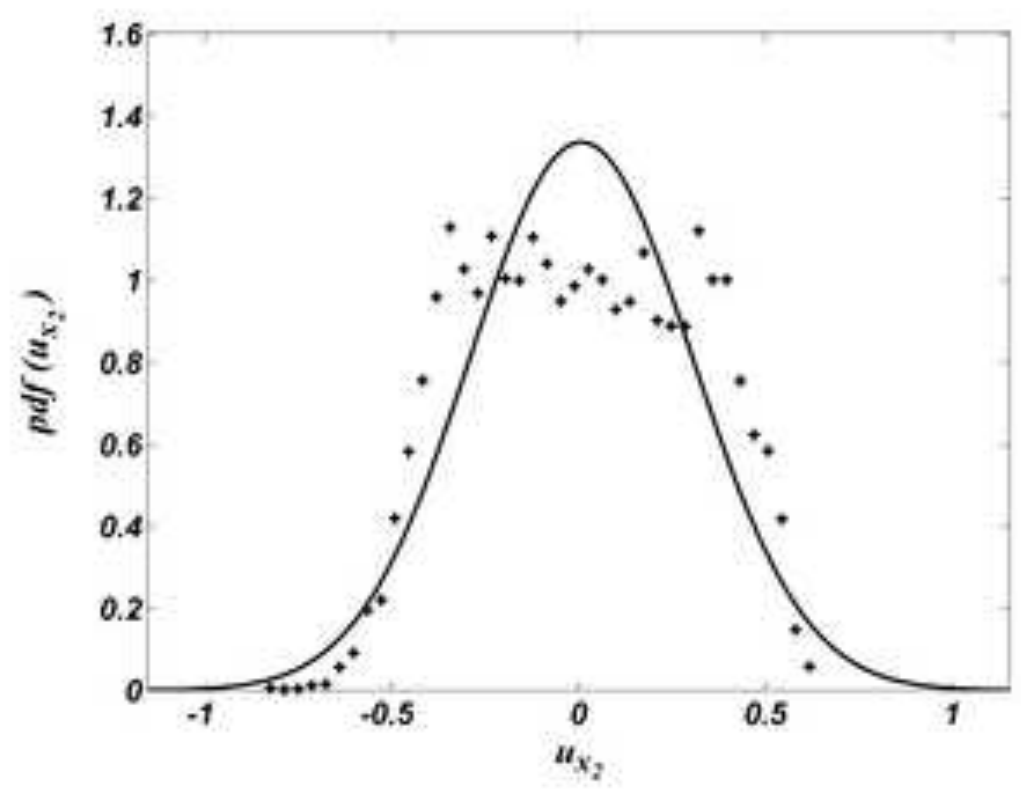

Cable 2

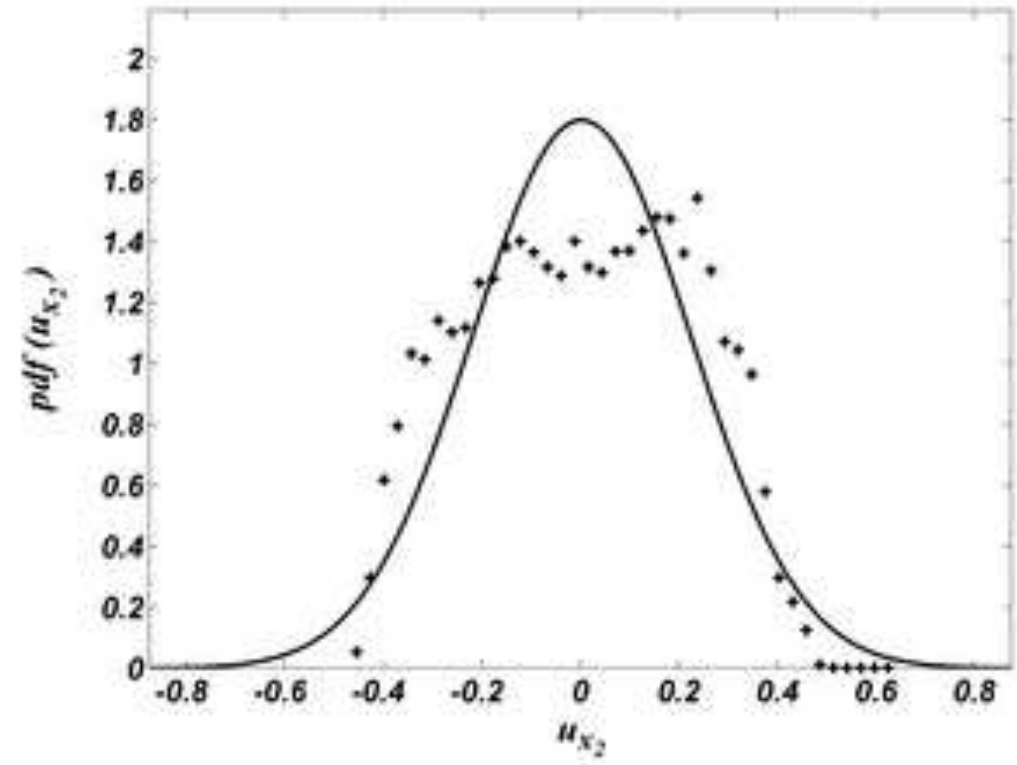

Cable 4

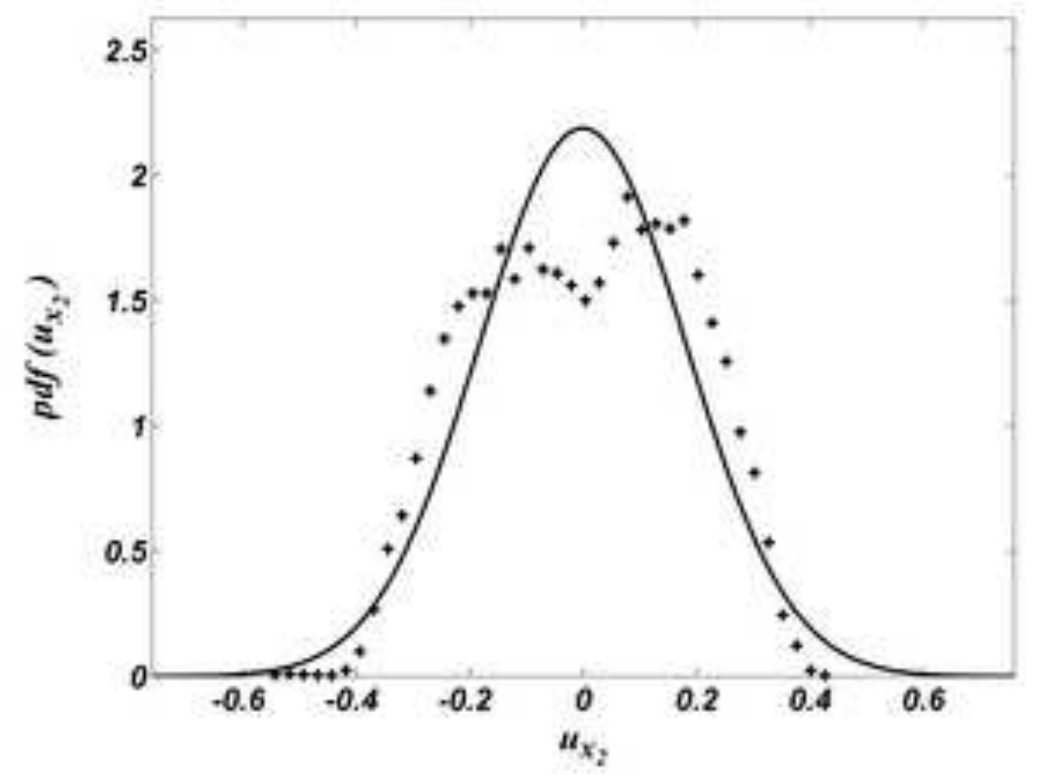




\section{Cable 1}

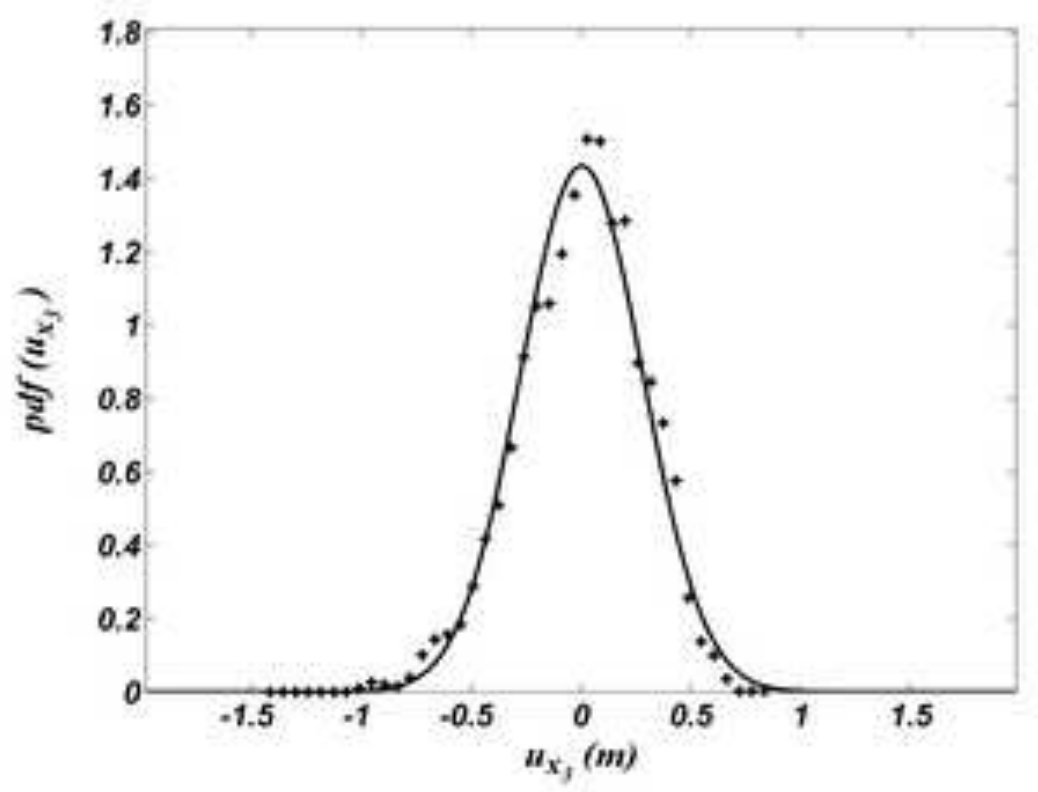

\section{Cable 3}

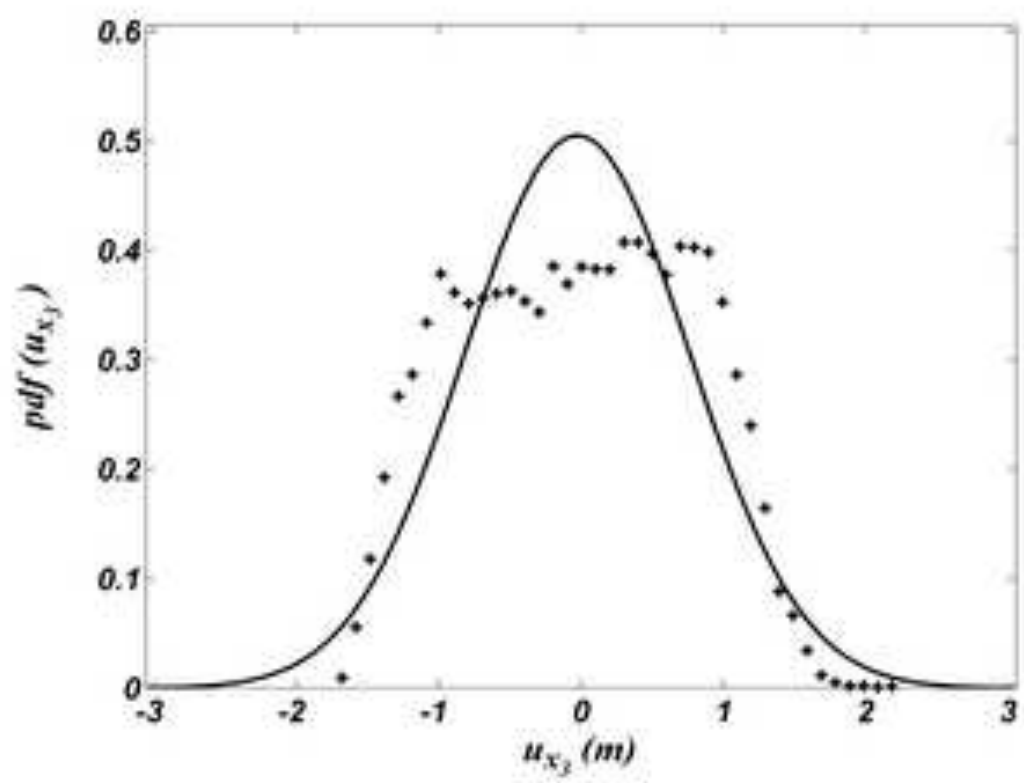

Cable 2

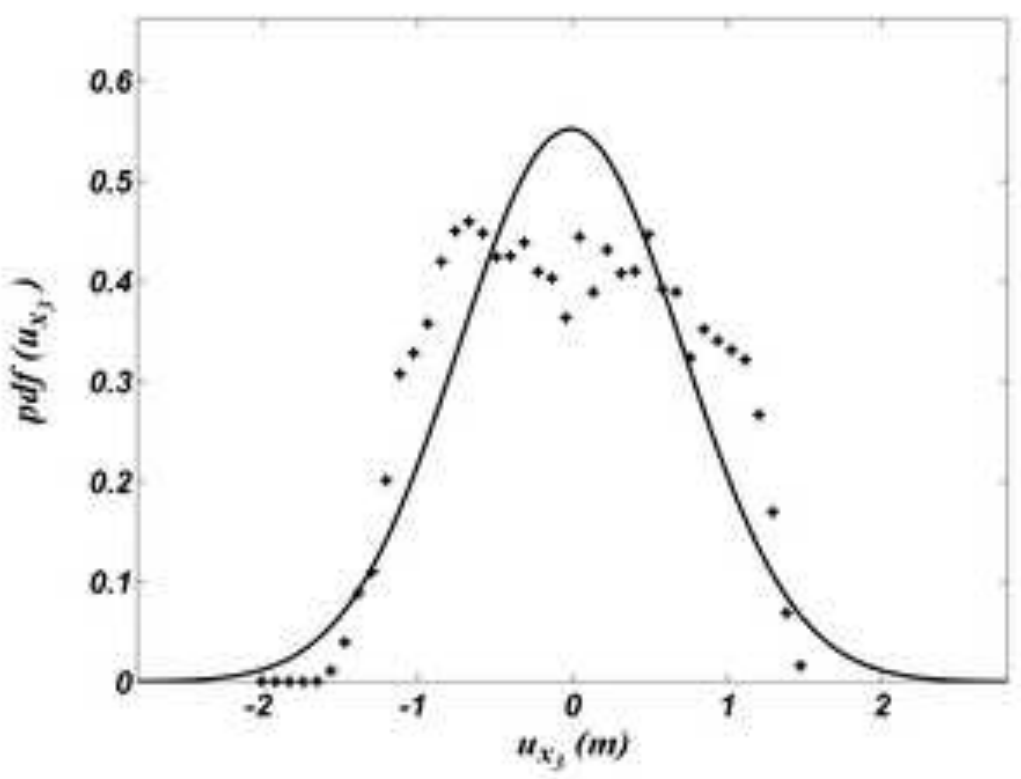

Cable 4

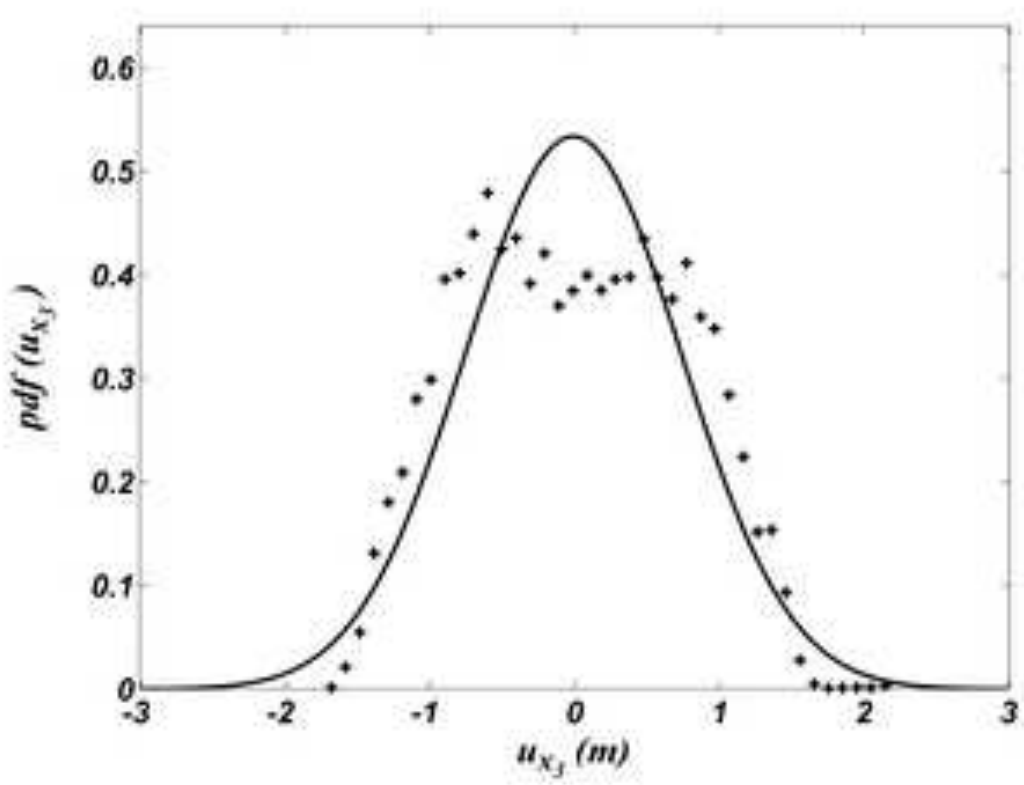


Cable 1

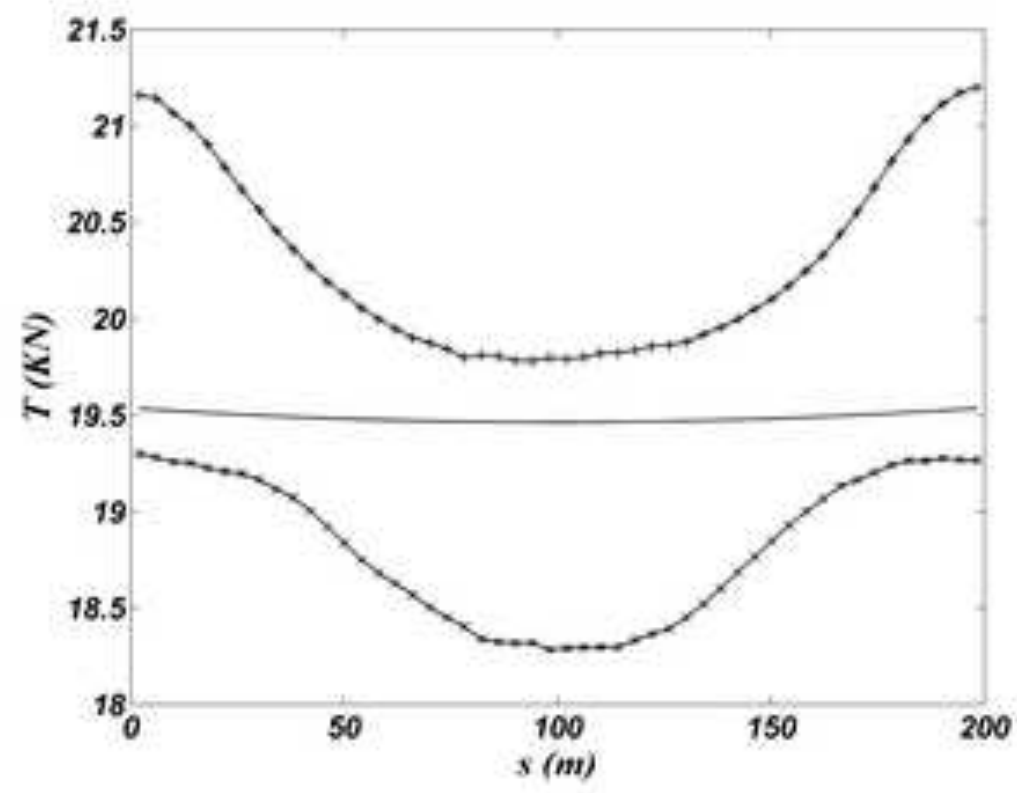

Cable 3

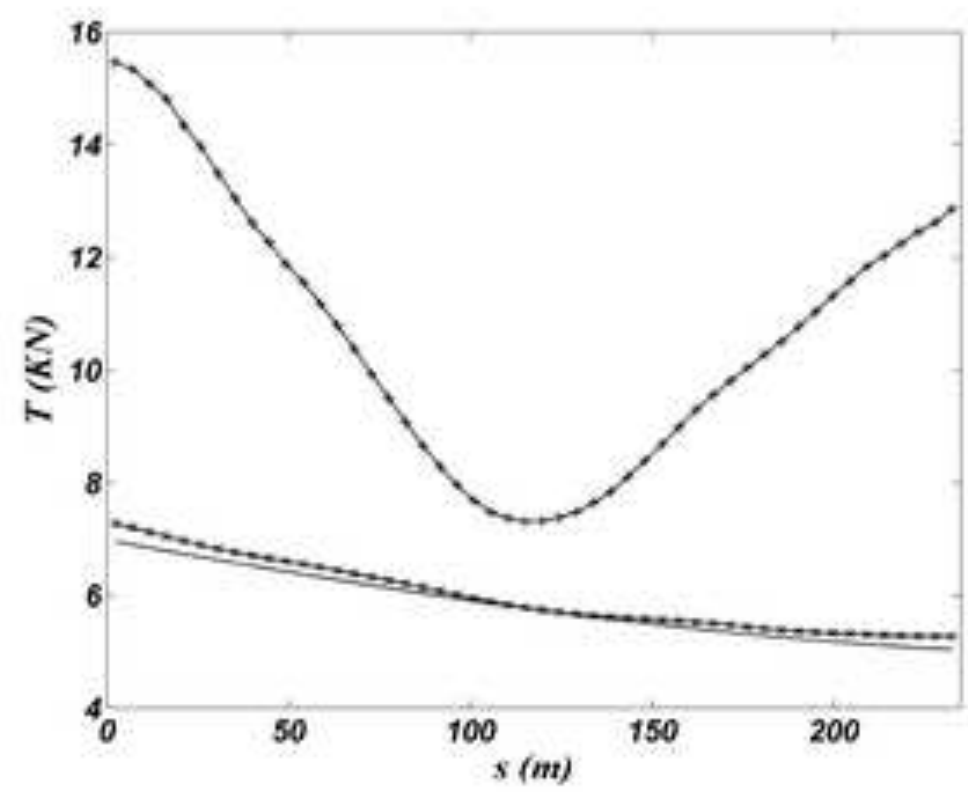

Cable 2

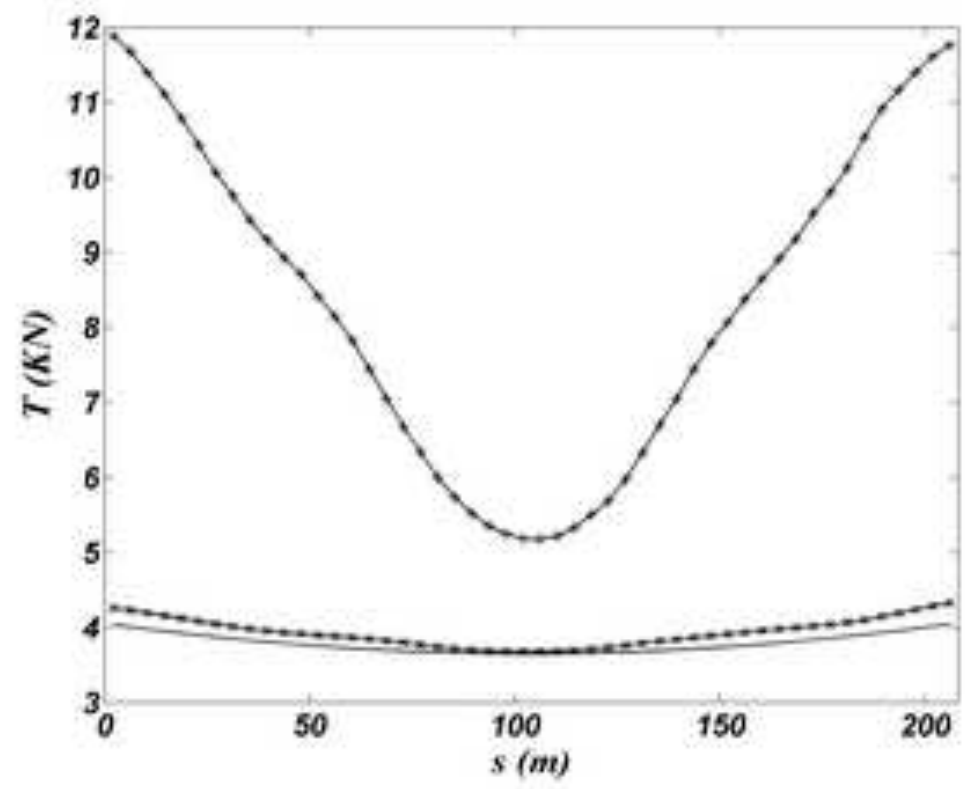

Cable 4

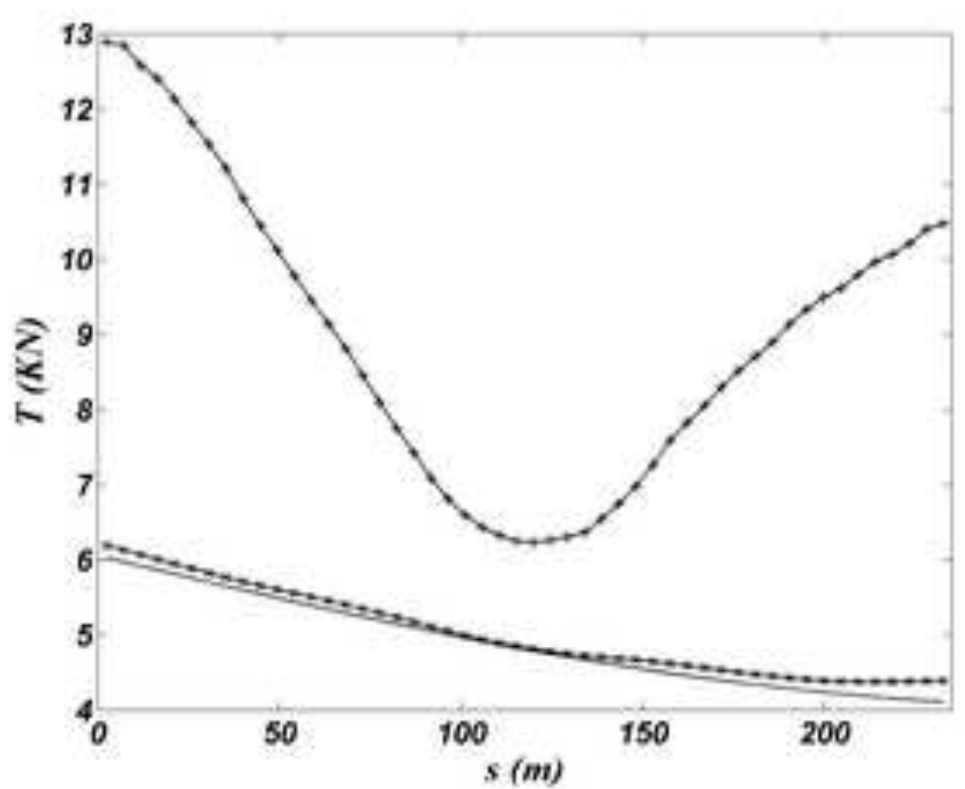




\section{ACCEPTED MANUSCRIPT}

Table 1

\begin{tabular}{cccccccccccc}
\hline Cable & $\begin{array}{c}b \\
(\mathrm{~m})\end{array}$ & $\begin{array}{c}E \\
\left(\mathrm{~N} / \mathrm{m}^{2}\right)\end{array}$ & $\begin{array}{c}A \\
\left(\mathrm{~m}^{2}\right)\end{array}$ & $\begin{array}{c}m \\
(\mathrm{Kg} / \mathrm{m})\end{array}$ & $\begin{array}{c}d_{H} \\
(\mathrm{~m})\end{array}$ & $\begin{array}{c}\vartheta \\
(\mathrm{rad})\end{array}$ & $\begin{array}{c}d_{V} \\
(\mathrm{~m})\end{array}$ & $\begin{array}{c}\lambda^{2} \\
(\mathrm{~m})\end{array}$ & $\begin{array}{c}\varphi \\
(\mathrm{rad})\end{array}$ & $\rho_{s}$ \\
\hline \hline 1 & 0.0308 & $810^{10}$ & 0.000559 & 1.73 & 200 & 0 & 0.00 & 69.88 & 200.2 & $\pi / 2$ & 0.005 \\
2 & 0.0308 & $810^{10}$ & 0.000559 & 1.73 & 200 & 0 & 0.00 & 10493.4208 .0 & $\pi / 2$ & 0.005 \\
3 & 0.0308 & $810^{10}$ & 0.000559 & 1.73 & 200 & $\pi / 6$ & 115.47 & 2246.91235 .0 & $\pi / 2$ & 0.005 \\
4 & 0.0308 & $810^{10}$ & 0.000559 & 1.73 & 200 & $\pi / 6$ & 115.47 & 3387.22235 .0 & $\pi / 4$ & 0.005 \\
\hline
\end{tabular}




\begin{tabular}{|c|c|}
\multicolumn{1}{c|}{} & ACCEPTED \\
\hline Non condensed & Condensed \\
\hline 0.692 & 0.692 \\
\hline 1.386 & 1.386 \\
\hline 1.521 & 1.386 \\
\hline 2.081 & 2.021 \\
\hline 2.294 & 2.081 \\
\hline 2.779 & 2.778 \\
\hline 3.196 & 2.778 \\
\hline 3.478 & 3.441 \\
\hline 3.976 & 3.478 \\
\hline 4.182 & 4.182 \\
\hline
\end{tabular}




\section{ACCEPTED MANUSCRIPT}

Table 3

\begin{tabular}{|c|rrr|rrr|rrr|}
\hline & \multicolumn{3}{|c|}{ Standard deviation $(m)$} & \multicolumn{3}{|c|}{ Skewness } & \multicolumn{3}{c|}{ Kurtosis } \\
Cable & $u_{x_{1}}$ & $u_{x_{2}}$ & $u_{x_{3}}$ & \multicolumn{1}{c|}{$u_{x_{1}}$} & \multicolumn{1}{c|}{$u_{x_{2}}$} & \multicolumn{1}{c|}{$u_{x_{3}}$} & \multicolumn{1}{c|}{$u_{x_{1}}$} & \multicolumn{1}{c|}{$u_{x_{2}}$} & $u_{x_{3}}$ \\
\hline 1 & 0,0008 & 0,0848 & 0,2779 & $-0,0735$ & $-0,1973$ & $-0,4065$ & 3,0473 & 2,8802 & 3,3215 \\
\hline 2 & 0,0108 & 0,2217 & 0,7229 & 0,0189 & $-0,0512$ & 0,0443 & 2,9220 & 1,9645 & 1,9488 \\
\hline 3 & 0,1648 & 0,2984 & 0,7901 & $-0,0172$ & 0,0092 & $-0,0297$ & 1,9778 & 1,9635 & 1,9627 \\
\hline 4 & 0,1002 & 0,1822 & 0,7472 & 0,1009 & $-0,0744$ & 0,0501 & 2,0766 & 2,0410 & 2,0244 \\
\hline
\end{tabular}

